\title{
Characteristics of Natural Fractures in an Ultradeep Marine Carbonate Gas Reservoir and Their Impact on the Reservoir: A Case Study of the Maokou Formation of the JLS Structure in the Sichuan Basin, China
}

\author{
$\mathrm{Hu} \mathrm{Li}$,* Qin Wang, Qirong Qin,* and Xinyu Ge
}

Cite This: https://doi.org/10.1021/acs.energyfuels.1c01581

ABSTRACT: The primary gas layer of the Maokou Formation of the JLS structure in the Sichuan Basin is a typical pore-fracture carbonate gas reservoir. Natural fractures (mainly tectonic fractures) serve as the critical factor in improving the reservoir's physical properties. The characteristics, formation mechanisms of natural fractures, and their impact on the reservoir are analyzed using the core, thin slice, full microresistivity imager imaging logging, production testing, and the Monte Carlo method multiple approximations. The results show that the fractures in the Maokou Formation reservoir generally refer to shear fractures of a tectonic origin, with the characteristics of a medium scale $(10-20 \mathrm{~cm})$, a large inclination angle (45$90)$, a high density (greater than $\left.5 \mathrm{~m}^{-1}\right)$, a medium opening $(1-3 \mathrm{~mm}$ ), and a low filling degree. There are three primary formation stages of natural fractures in the area, the Indosinian stage $(232-210 \mathrm{Ma})$, the early-middle

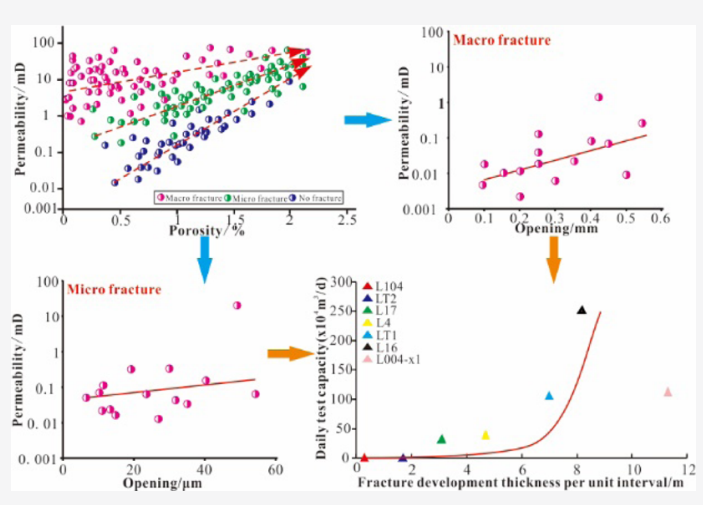
Yanshanian stage (145-90 Ma), and the late Yanshanian-Himalayan stage (90-0 Ma). The corresponding principal stress directions are NW, near-SN, and NNW, respectively. Natural fractures have a positive effect on the improvement of reservoir physical properties. The fracture's physical parameters show a good positive correlation with the physical properties of the reservoirs. The fracture parameters influence the reservoir's physical properties ranked from biggest to smallest: opening, length, and density. The greater the development degree of fractures, the greater the corresponding natural gas production capacity. The research results provide a new technical method for quantifying the influence of fracture parameters on reservoir's physical properties.

\section{INTRODUCTION}

Marine carbonate gas reservoirs play a significant role in natural gas production in the Sichuan Basin, accounting for $85 \%$ of the conventional natural gas resources in the Basin. ${ }^{1-3}$ Generally speaking, the storage space types of the carbonate reservoir mainly refer to caves, pores, and fractures (especially tectonic fractures). ${ }^{4-7}$ As an essential type of storage space, fractures have positive significance for improving the physical properties of carbonate reservoirs, particularly for deep carbonate reservoirs with a buried depth of more than 5000 m..$^{8-12}$ Since carbonate reservoirs are primarily formed in early times with deep burial depths and have usually undergone multiple stages of tectonic movement and various types of diagenesis transformations, the natural fracture network is rendered rather complicated. ${ }^{13-16}$ It is of great significance for further fracture prediction, optimal selection of favorable development areas, well location deployment, etc., to figure out the characteristics of natural fractures in carbonate reservoirs and work out the mechanism of fracture formation. ${ }^{17-20}$ Over the years, scholars at home and abroad have conducted systematic research on the formation models, development characteristics, influencing factors, formation mechanism, and distribution laws of natural carbonate fractures, which effectively guide the exploration and development of carbonate reservoirs. ${ }^{1,8-10,21-28}$ It is generally believed that natural fractures can effectively improve the reservoir's physical properties, which increases the reservoir's porosity and dramatically enhances its permeability. ${ }^{1,8-10}$ However, the quantitative relationship between the development characteristic parameters of natural fractures and the physical parameters of fractures and reservoirs has nearly been blank. Figuring out the impact of different parameters of natural

Received: May 24, 2021

Revised: July 19, 2021 

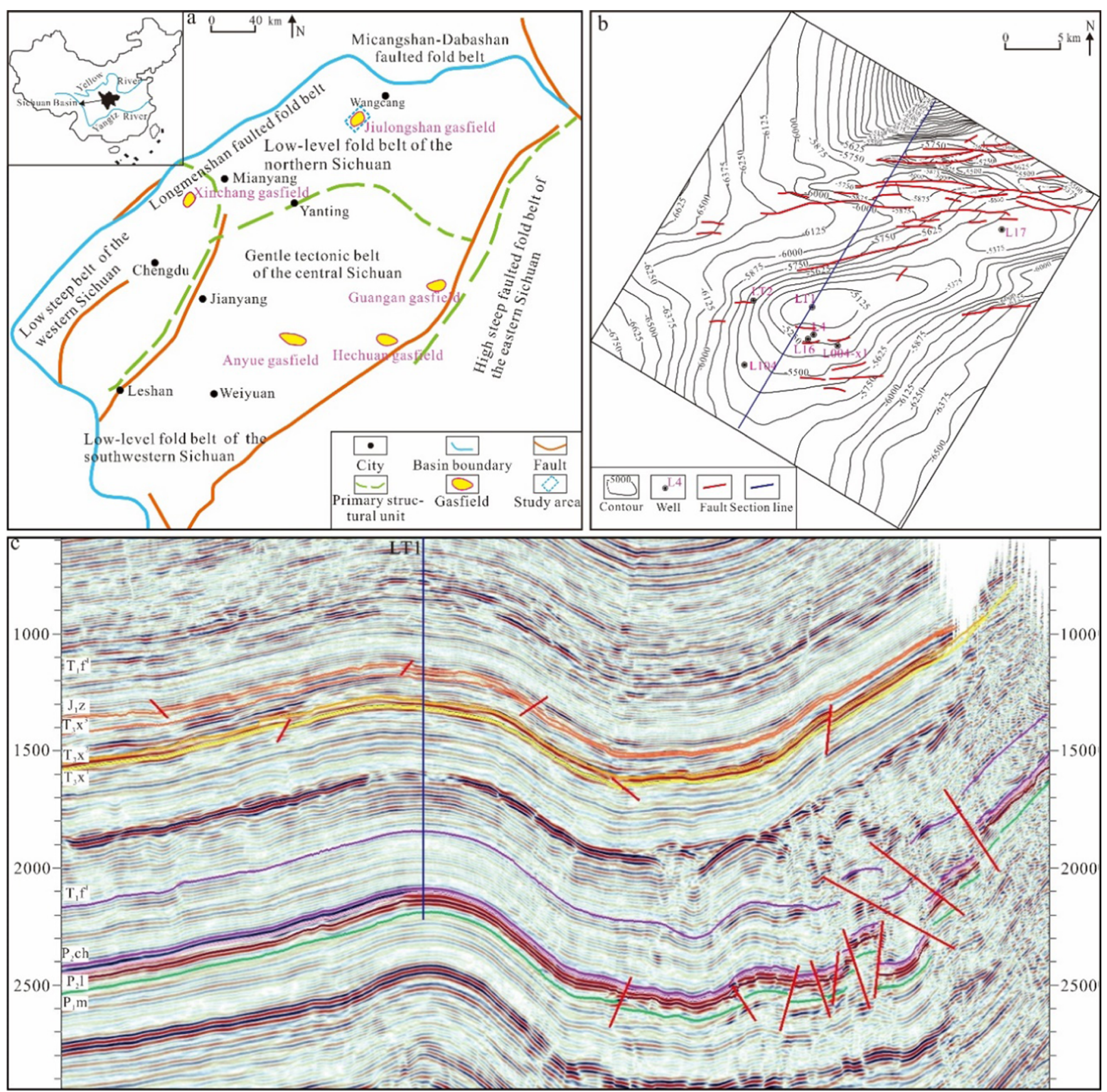

Figure 1. Regional structural characteristics of the study area. (a) Location of structure in the study area, ${ }^{9}$ (b) structural map of the Maokou Formation in the study area, ${ }^{1}$ and (c) seismic profile across the well LT1.

fractures on reservoirs has essential significance in guiding the exploration and development of carbonate oil and gas.

The JLS structure lies in the northwestern part of the Sichuan Basin, and the Permian Maokou Formation has a burial depth of more than $5000 \mathrm{~m}$, which belongs to ultradeep carbonate deposits. In the past years, significant advances have been made in the marine carbonate reservoirs of the Maokou Formation in the JLS structure. High-yield gas flows have been obtained in many wells, but the test production of the wells varies greatly. For example, well L16 has a test daily gas production of $252 \times 10^{4} \mathrm{~m}^{3}$, well L004-x1 has $112 \times 10^{4} \mathrm{~m}^{3}$, and well L4 $21 \times 10^{4} \mathrm{~m}^{3.29}$ Well LT1 located higher in the structure has no reservoir according to logging interpretation (not tested). Such instances were found in quite a few development wells in the neighboring areas. Research has testified that natural fractures are of great significance to improving the physical properties of carbonate reservoirs in this area. ${ }^{1}$ Based on the data of rock core, thin slice, imaging logging, production test, etc., the natural fracture characteristics, formation mechanism, and the influence of fracture parameters on physical properties of reservoirs were discussed, which provide a geological basis for further development and adjustment of the gas field.

\section{GEOLOGICAL BACKGROUND}

The JLS structure is located at the front edge of the fault-fold structural belt on the Micangshan platform margin uplift and the low-level fold belt in northern Sichuan. It belongs to a local 


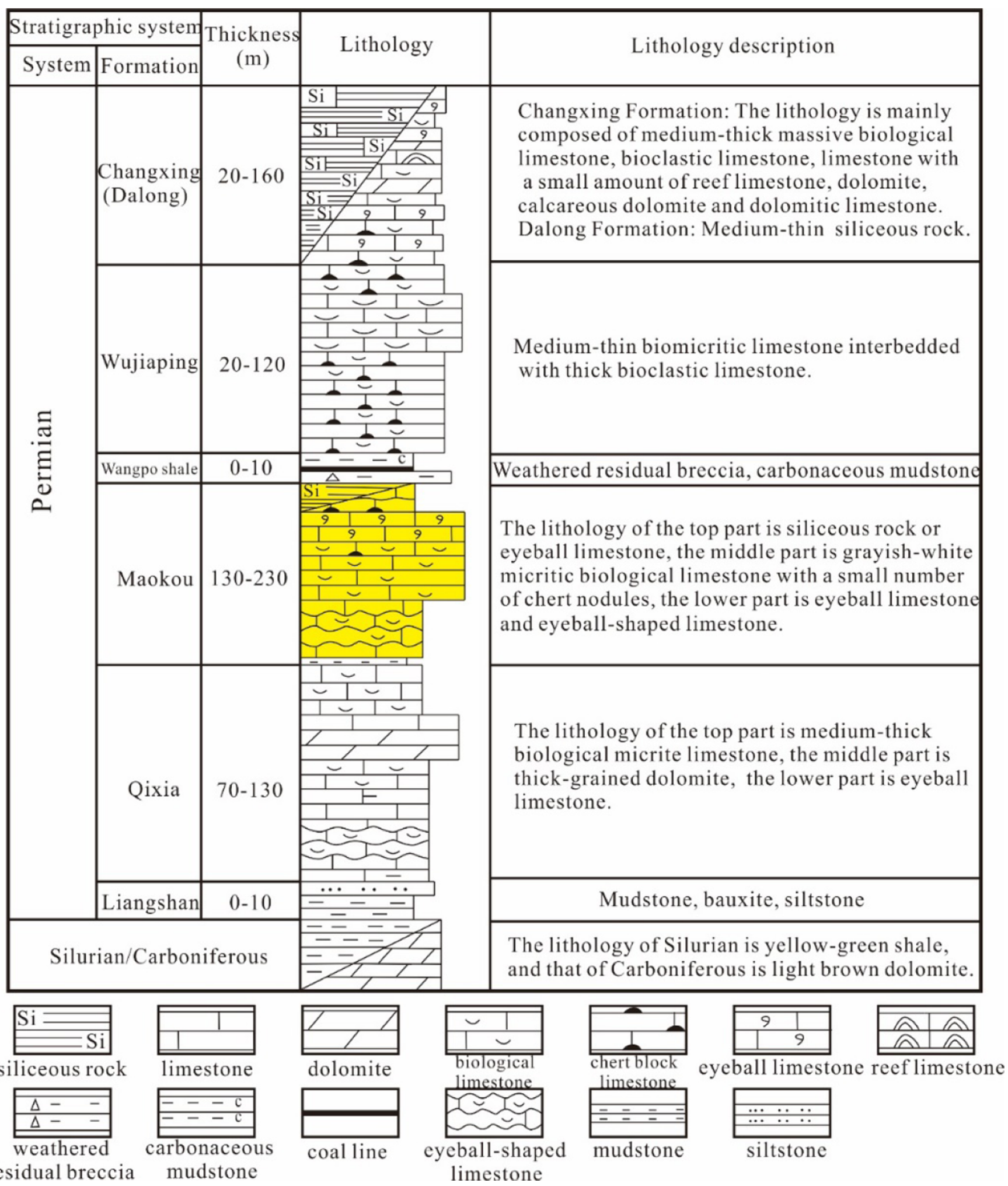

Figure 2. Histogram of stratigraphic characteristics in the study area. ${ }^{29}$

structure in the marginal depression zone in the northern part of the platform. To the west lies the Longmenshan nappe faultfold structural belt, to the north is the Micangshan platform margin uplift, and to the south is the low-gentle structural belt in northern Sichuan (Figure 1a). ${ }^{1,1322}$ Its distribution is undoubtedly limited by the Longmenshan nappe belt, the Micangshan platform margin uplift, and the Bazhong-
Tongjiang rotation structure system. The Maokou Formation structure in the study area is a large short-axis anticline, with an axis direction approximate to NE-SW and two high points of the main body of JLS and the Tadongping. The faults are mainly developed in the JLS structure and the high points in the north, with the main strikes of NE and near-EW directions. The strikes of folds are in the NEE direction (Figure 1b,c). 

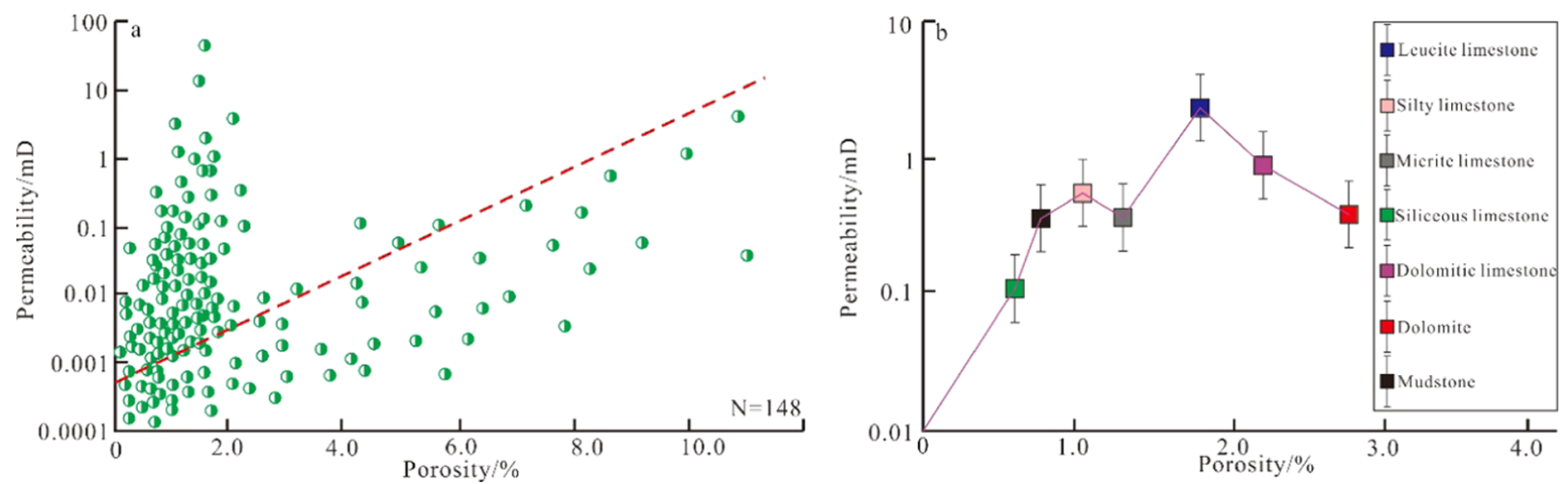

Figure 3. Physical properties of the reservoir in the Maokou Formation in the study area. (a) Porosity-permeability cross plot and (b) physical properties of different rock cores.
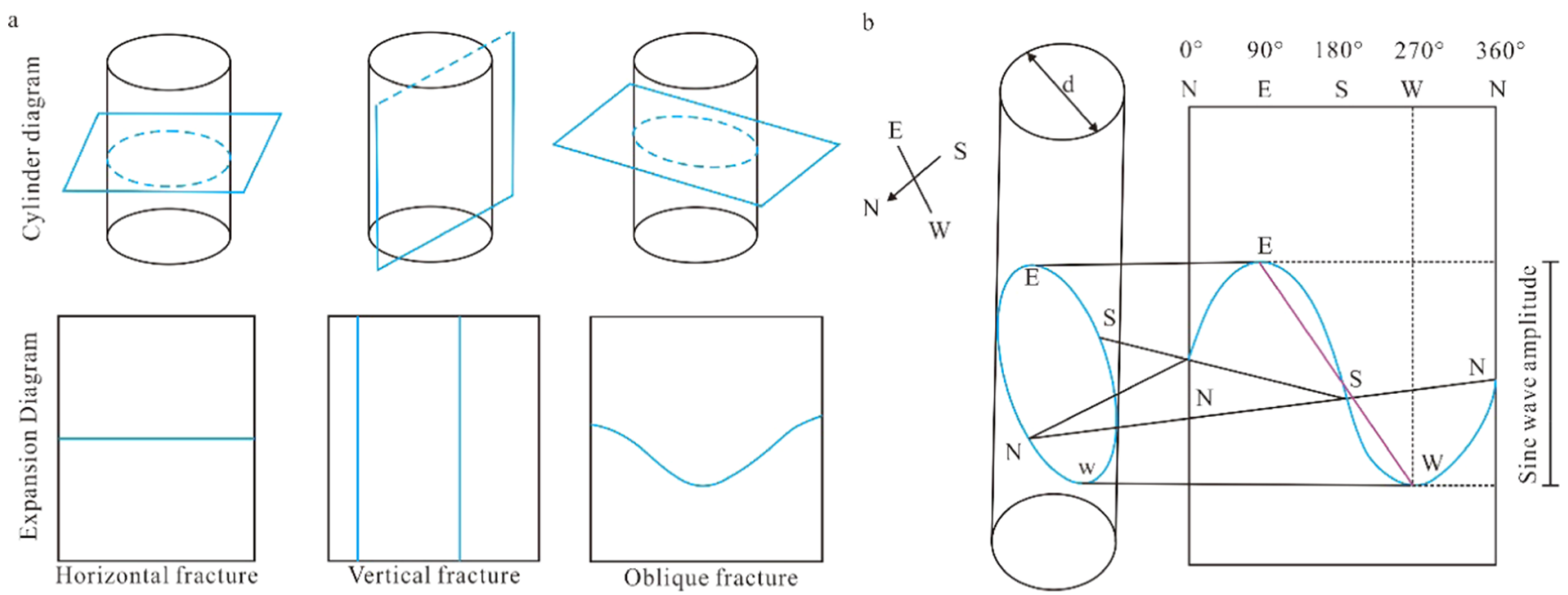

Figure 4. Schematic diagram of imaging logging to identify the fractures. (a) Schematic diagram of imaging logging images and (b) schematic diagram of imaging logging to determine fracture occurrence.

The faults differ significantly from folds in strikes, indicating that the study area is subject to the effects of multistage and multidirectional tectonic stress. ${ }^{1}$

The Permian strata in the JLS area mainly include the Upper Permian Changxing Formation and Wujiaping Formation and the Lower Permian Qixia Formation and Maokou Formation. ${ }^{29}$ The faunas in the upper and lower Permians differ noticeably, such as fusulinid, brachiopod, coral, etc., and the Wangpo Shale at the bottom of the Upper Permian Wujiaping Formation is pseudoconformed with the limestone or siliceous rock at the top of the Lower Permian Maokou Formation (Figure 2). 1,13,22,29 The thickness of the Maokou Formation is between 130 and $230 \mathrm{~m}$, which can be segmented into four from bottom to top. The first and second segments are dominated by dark gray micrite bioclastic limestone, the third segment is light gray-gray white bioclastic limestone and leopard porphyry limestone intercalated with dolomite, with developed dissolution pores and fractures, and the fourth segment mainly refers to siliceous shale and micrite limestone, most of which are denuded and the residue of which is relatively thin. ${ }^{30}$ Among them, the third segment is the major producing layer.

Given the measured porosity and permeability data of rock core samples, it can be known that the porosity of the Maokou Formation reservoir ranges from $0.12-16.51 \%$, with an average of $1.56 \%$, and the permeability ranges from $0.00025-98 \mathrm{mD}$, with an average of $1.66 \mathrm{mD}$. The correlation between reservoir porosity and permeability can be divided into two areas. More than $80 \%$ of the data points are concentrated in the area above the trend line. The porosity is generally less than $2.0 \%$, and the correlation between porosity and permeability is poor. Such a reservoir is mainly impacted by karst caves and natural fractures featuring low porosity and high permeability. ${ }^{31-34}$ The remaining data points display a good positive correlation, with fewer corresponding data points (Figure 3a).

Overall, the study area is dominated by the pore-fracture type of reservoirs, and karst caves and fractures have a good modifying effect on the physical properties of the reservoir. ${ }^{35}$ Additionally, there are statistics about the average physical properties of different lithologies in the study area, showing that bioclastic sprite limestone, silt bioclastic limestone, and medium-coarse crystal dolomite have excellent physical properties. ${ }^{36}$ This type of lithology is mainly distributed in the shoal facies reservoir in the third section of the Maokou Formation (Figure 3b).

\section{SAMPLES AND METHODS}

This research contains the primary data of rock core, thin slice, imaging logging, and production testing data, etc., which were mainly used for the calculation and statistics of the basic parameters of the fractures (length, opening, density, and filling degree), fracture occurrence, and physical parameters. The $162.9 \mathrm{~m}$ cores of seven 


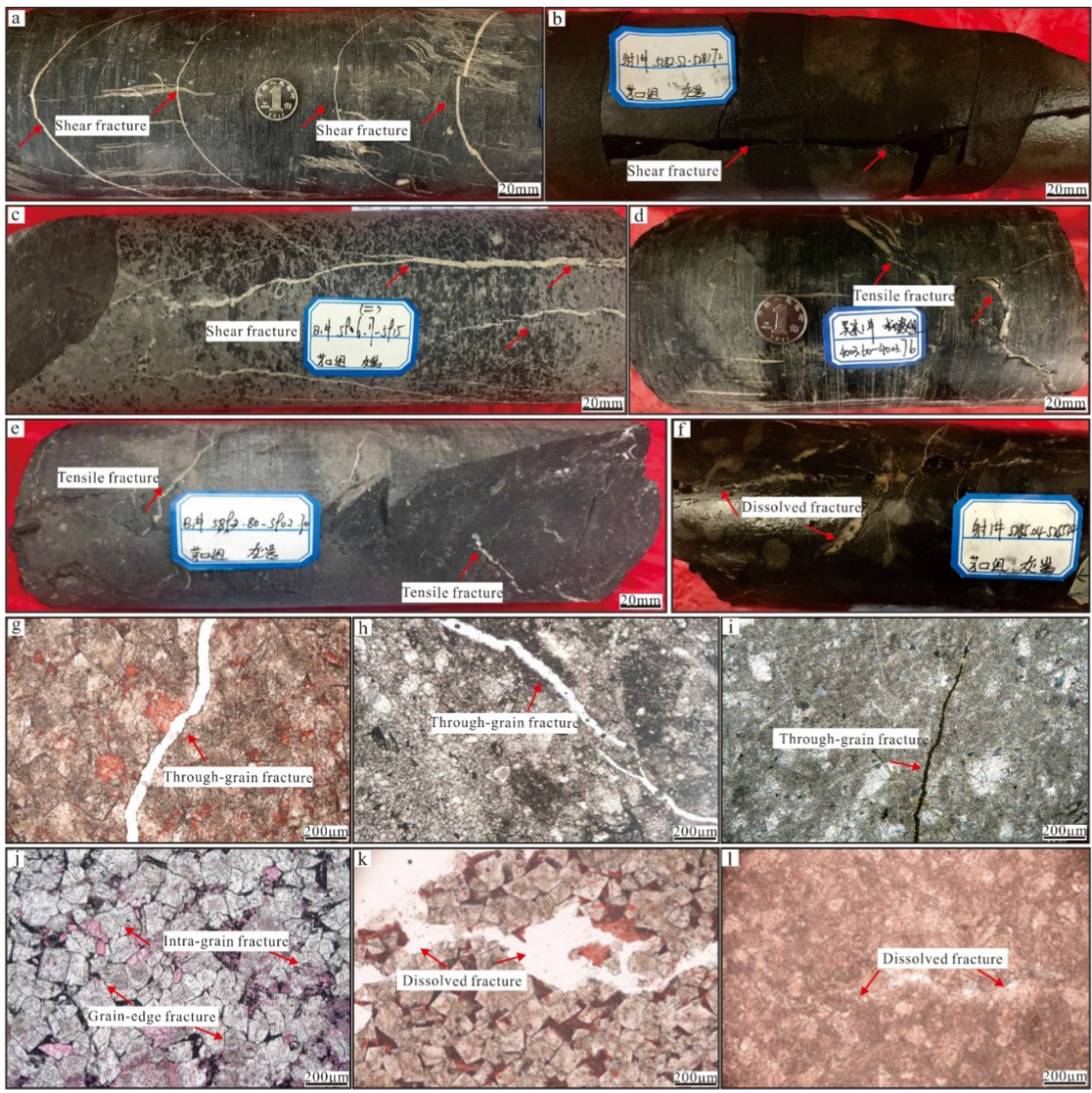

Figure 5. Types and characteristics of macrofractures and microfractures. (a) Well WJ1, 3525.84-3826.22 m, shear fracture, parallel arrangement, and fulfilled by calcite. (b) Well S1, 5282.52-5282.72 m, shear fracture, and unfilled. (c) Well B1, 5906.17-5906.35 m, shear fracture, and fulfilled by calcite. (d) Well WJ1, 4003.60-4003.76 m, tensile fracture, and the fracture surface is curved and half-filled by calcite. (e) Well B1, 5892.80$5893.06 \mathrm{~m}$, and tensile fracture. (f) Well B1, 5285.04-5285.24 m, and dissolved fracture. (g) Well L004-x1, 6178.00 m, through-grain fracture, and unfilled. (h) Well L17, $5900.00 \mathrm{~m}$, through-grain fracture, and unfilled. (i) Well L17, $5969.00 \mathrm{~m}$, through-grain fracture, and unfilled. (j) Well L17, $5864.91 \mathrm{~m}$, grain-edge fracture, and intragrain fracture. (k) Well L17, $6179.00 \mathrm{~m}$, and dissolution fracture. (1) Well L004-x1, 6168.00 m, and dissolution fracture.

wells (LT1, LT2, L16, L17, L104, and L004-x1) were selected for fracture observation, and 546 photos of typical fractures were obtained. Overall, 34 thin slices were produced, 360 thin slices to observe were made, and 51 microcrack photos were obtained. Imaging logging data of five wells were collected, and interpretation and statistics of fracture strikes and dips were conducted. Conventional logging data of seven wells were collected to identify the longitudinal fracture section

3.1. Interpretation of Imaging Logging Fractures. The imaging logging image is a very intuitive expanded view of directional coring profiles, displaying fracture information. The imaging logging identifying fractures is mainly based on the difference between the electrical resistivity of the fractured formation and that of the surrounding rock. In the formation with fractures, thanks to mud intrusion, the electrical resistivity of the fracture is significantly lower than that of the surrounding rock, which is shown as dark stripes on the imaging map. ${ }^{9,10,37-40}$ Different causes and different types of fractures have different image characteristics (Figure 4a). Therefore, imaging logging can be employed to identify fracture types, precisely calculate fracture occurrence, and analyze the development degree of the fractures.

The imaging logging image is an expanded view to the right along the due north direction of the borehole wall. The complete effective fracture is a black sine curve of a wavelength on the electrical resistivity image. Based on the characteristics and distribution of the sine curve, the orientation and inclination of fractures can be determined. The intersection part will be an ellipse if a plane that is neither parallel nor perpendicular to the well axis intersects with the cylindrical borehole, which is displayed as a sine wave curve corresponding to the expanded view (Figure $4 \mathrm{~b}$ ). The distance between the maximum value of the sine wave curve and the minimum mirrors the inclination of the fracture relative to the horizontal plane. $^{24,41-43}$ The line connecting the lowest point and the highest point of the sine wave represents the tendency line of the plane, and the azimuth at the lowest point (valley) of the sine wave curve displays the strike of the fracture surface. The fracture inclination 

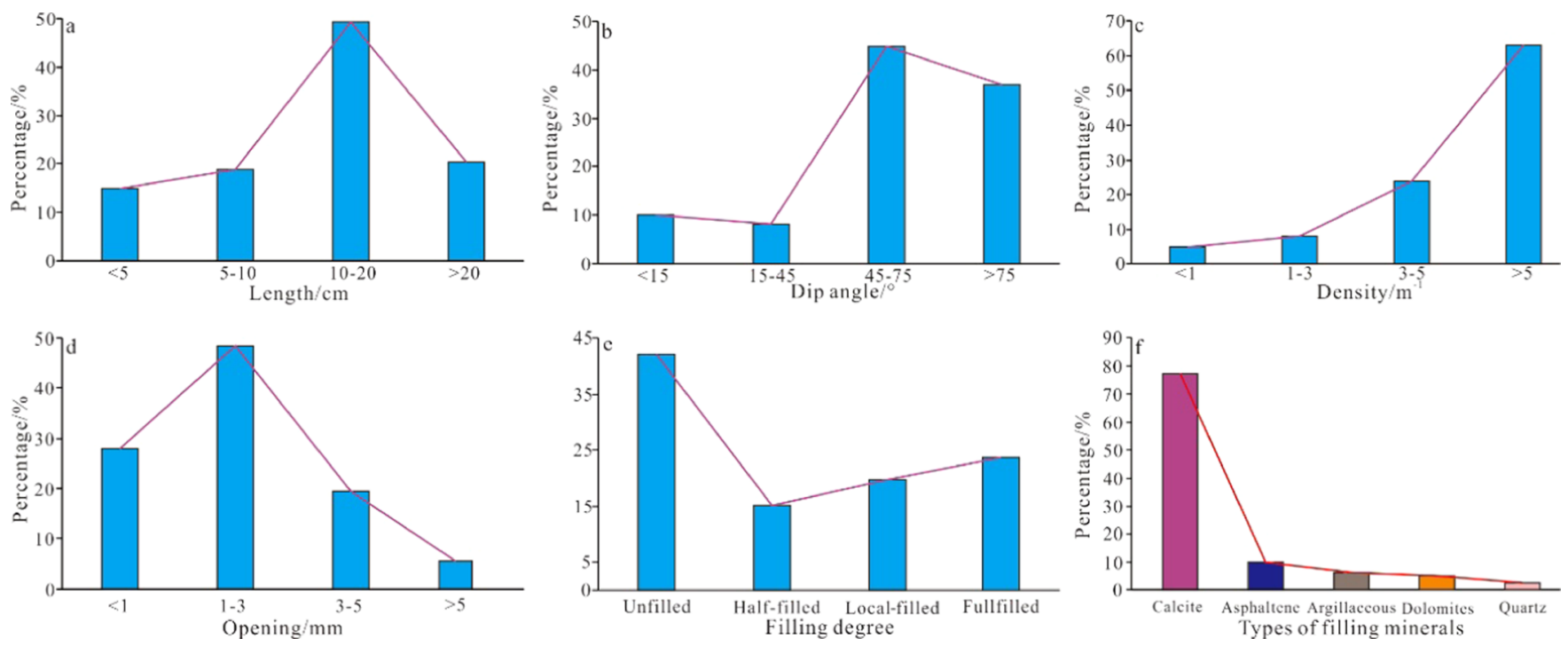

Figure 6. Development characteristics of the macrofractures of the Maokou Formation in the study area. (a) Fracture length, (b) fracture dip, (c) fracture density, (d) fracture opening, (e) fracture filling degree, and (f) fracture filling minerals.

angle can be expressed as the ratio of the amplitude of the sine wave to the diameter of the well

$$
\theta=\operatorname{arctg} \frac{h}{d}
$$

where $d$ is the diameter of the well and $h$ is the vertical distance between the highest point and the lowest point of the S-shaped (sine wave) on the imaging logging.

3.2. Calculation of Fracture Physical Parameters. The fracture length, opening, linear density, areal density, etc., can be accurately counted on rock cores and thin slices. These parameters are significant indicators for evaluating the impact of fractures on the reservoir. With these data, the physical parameters (porosity and permeability) of fractures can be calculated. Based on the fracture characteristic parameters obtained based on rock cores and thin slices, the physical properties of fractures were calculated with the Monte Carlo multiple approximation method. ${ }^{44,45}$

The Monte Carlo method is based on probability theory and mathematical statistics to solve mathematical physics and engineering technology problems. The specific issue first establishes a probability model, carries the random test to the model, and statistically solves it. $^{46-48}$ Specifically, the Monte Carlo principle is a way to calculate the statistical characteristics of the required parameters by observing the model and the process or conducting sampling experiments. Thus the relationship between $\mathrm{A}$ and $\mathrm{B}$ is solved. The main idea of the conventional Monte Carlo method is as follows: assuming that the sampling times are $T$, the sampling values are substituted into the functional function $G$ one by one to obtain functional function values $\left(G_{1}, G_{2} \ldots, G_{\mathrm{T}}\right)$, and then the times $\left(N_{\mathrm{F}}\right)$ less than 0 in the functional function value are judged one by one, and the ratio of the failure times $\left(N_{\mathrm{F}}\right)$ to the total sampling times $(T)$ is defined as the failure probability. ${ }^{49}$

This method adopts mathematical probability algorithms to simulate and calculate the fracture parameters of rock samples, thereby yielding the optimal representative and reliable values.

The calculation methods of fracture permeability and porosity in rock samples are, respectively, ${ }^{50}$

$$
\begin{aligned}
& K_{\mathrm{f}}=C \cdot\left(\frac{1}{A_{\mathrm{s}}}\right) \sum_{i=1}^{n} L_{i} \cdot B_{i}^{3} \\
& \phi_{\mathrm{f}}=\left(\frac{1}{A_{\mathrm{s}}}\right) \sum_{i=1}^{n} L_{i} \cdot B_{i}
\end{aligned}
$$

where $A_{s}$ is the surface area of the rock samples, $L_{i}$ is the fracture length, $B_{i}$ is the fracture opening, and $C$ is the proportional coefficient, which depends on the geometrical morphology of the fractures in the rock. If the fractures are parallel to each other, then the value of $C$ is $3.42 \times 10^{4}$.

\section{RESULTS}

4.1. Characteristics of Natural Fractures. 4.1.1. Formation Types of Fractures. By observing $162.9 \mathrm{~m}$ cores of seven wells in the study area, the natural fractures in the carbonate reservoirs of the Maokou Formation are mainly classified into two types by formation causes, i.e., tectonic fractures and diagenetic fractures, of which tectonic fractures are the most widely developed. Therefore, tectonic fractures have the most significant impact on reservoir physical properties, which is also the most important fracture type studied in this paper. Tectonic fractures are divided into shear fractures and tensile fractures (the former dominates). 9,10,51 According to the fracture inclination, tectonic fractures are classified into horizontal fractures $\left(0-15^{\circ}\right)$, low-angle fractures $\left(15-45^{\circ}\right)$, high-angle fractures $\left(45-75^{\circ}\right)$, and vertical fractures $\left(75-90^{\circ}\right)$. Normally, the shear fractures are relatively regular in shape with straight and smooth surfaces. Their occurrence distribution is stable, and they mostly emerge in groups with relatively a uniform distribution of fracture opening and the major filling of calcite. Occasionally, the shear fractures are arranged in an echelon or conjugate shear distribution (Figure $5 \mathrm{a}-\mathrm{c}$ ). Tensile fractures are generally irregularly curved with rough surfaces with an uneven fracture opening and a relatively short extension range. The filling of asphalt and calcite can be seen with noticeably different thicknesses of the filling minerals (Figure 5d,e). Diagenetic fractures include dissolved fractures, pressure-dissolved fractures, sutures, etc., among which dissolved fractures occupy the most. $^{52-54}$ This kind of a fracture is mainly formed by dissolution along the foundation of early fractures, the fracture opening is increased, and the surface is extremely irregular (Figure 5f). The number of pressure solution fractures in the study area is small, mainly due to the dissolution of soluble minerals under the static rock pressure of the overlying formation. They are mostly characterized by suture structure 


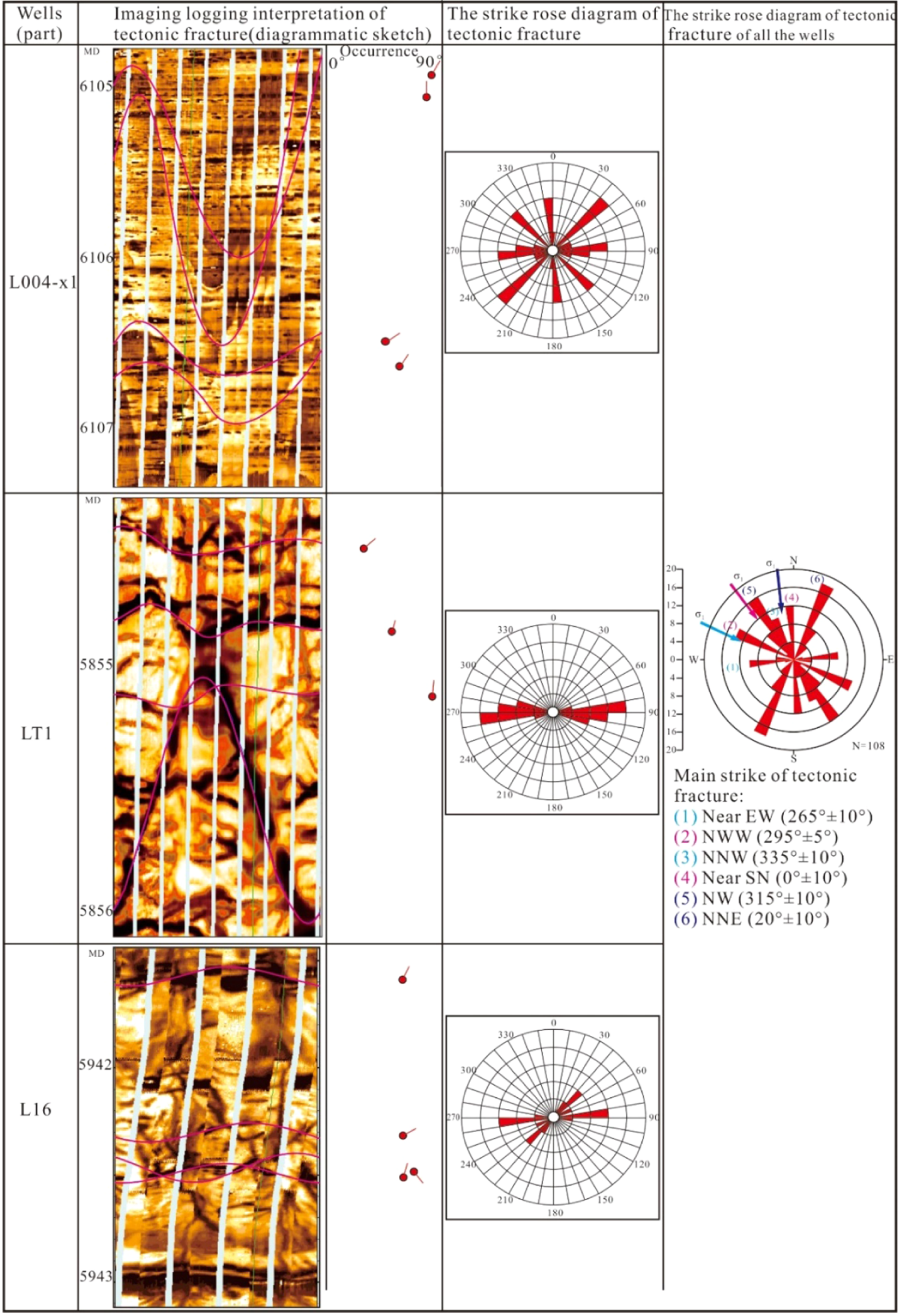

Figure 7. Fracture identification based on imaging logging interpretation. ${ }^{1}$

and make little contribution to the reservoir space and fluid seepage. $^{55-57}$ These fractures are intertwined to form a network and can remarkably change the permeability of the reservoir.
According to the positional relationship between the microfractures and the surrounding particles, they can be classified into through-grain fracture, grain-edge fracture, and intragrain fracture. ${ }^{13,23}$ By observing 360 thin slices, the edges 


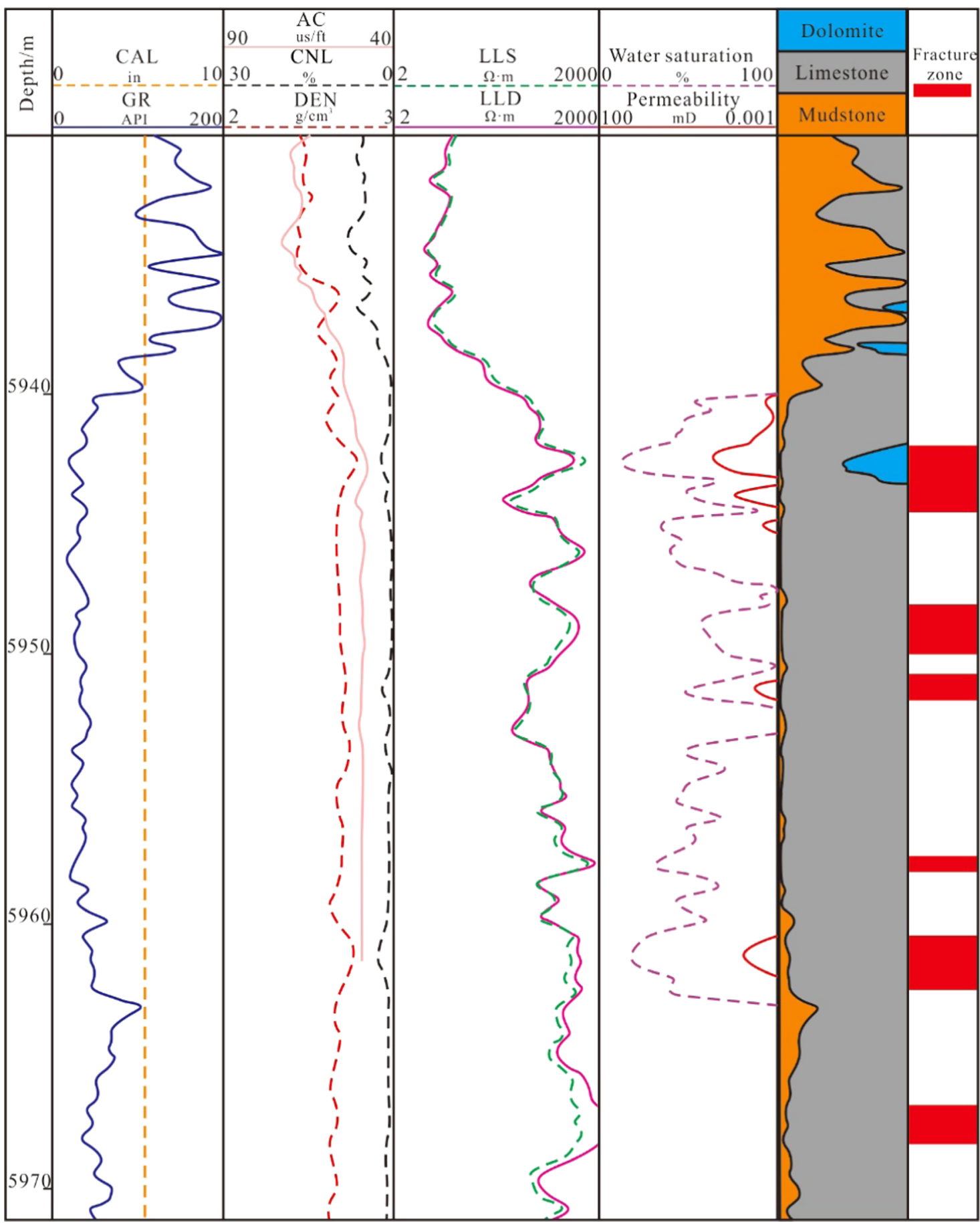

Figure 8. Fracture identification based on conventional logging interpretation.

of the through-grain fracture are primarily straight, larger in scale, longer in extension, and larger in the opening, which usually can cut through the grain and extend (Figure $5 \mathrm{~g}-\mathrm{i}$ ); Through-grain fractures are the major type of microfractures with a relative content of $65 \%$ and sound effectiveness so that they are an important fracture type for reservoir improvement. The grain-edge fracture mainly develops around the edge of a grain, which does not cut through the grain. It is largely distributed among particles and generally developed in a network shape. Such kind of a fracture is medium-sized, irregular in shape, and mostly curved (Figure $5 \mathrm{j}$ ). The single fracture has a short extension length, but this type of fracture has excellent interconnectivity with the two ends mostly connected with pores. So, it has remarkable effectiveness and a strong seepage ability. Intragrain fractures refer to the fractures inside grains, which do not cut through the edges of grains (Figure 5k), and they mainly develop along the joint direction of feldspar or quartz. Such types of fractures account for less than $10 \%$, with poor connectivity, and are invalid cracks in most cases. Due to the fluid action, the different fractures can be dissolved to form dissolution fractures (Figure 5k).

4.1.2. Characteristic Parameters of Fracture Development. Through core observations, the characteristic parameters of macrofractures were collected, mainly including the 
Table 1. Statistics of Macrofracture Parameters (Part)

\begin{tabular}{|c|c|c|c|c|c|c|c|}
\hline no. & well & depth $(m)$ & fracture length $(\mathrm{cm})$ & fracture opening $(\mathrm{cm})$ & fracture linear density $\left(\mathrm{m}^{-1}\right)$ & fracture permeability $(\mathrm{mD})$ & fracture porosity (\%) \\
\hline 1 & L17 & 5855.43 & 10 & 0.2 & 5 & 80.6 & 0.11 \\
\hline 2 & & 5859.89 & 4 & 0.1 & 2 & 106.7 & 0.03 \\
\hline 3 & & 5861.41 & 5 & 0.4 & 4 & 370.6 & 0.27 \\
\hline 4 & & 5866.30 & 25 & 0.8 & 3 & 428.8 & 0.35 \\
\hline 5 & & 5869.25 & 10 & 0.1 & 9 & 338.5 & 0.04 \\
\hline 6 & & 5201.77 & 7 & 0.2 & 1 & 149.8 & 0.11 \\
\hline 7 & & 5210.27 & 20 & 0.3 & 8 & 210.1 & 0.23 \\
\hline 8 & B1 & 5883.65 & 25 & 0.4 & 7 & 47.2 & 0.26 \\
\hline 9 & & 5891.65 & 22 & 0.2 & 4 & 95.6 & 0.37 \\
\hline 10 & S1 & 5282.52 & 12 & 0.6 & 2 & 348.8 & 0.02 \\
\hline 11 & & 5285.04 & 13 & 0.2 & 10 & 225.2 & 0.50 \\
\hline 12 & & 5284.78 & 15 & 0.4 & 2 & 148.3 & 0.30 \\
\hline
\end{tabular}

Table 2. Statistics of Microfracture Parameters (Part)

\begin{tabular}{|c|c|c|c|c|c|c|c|}
\hline no. & well & $\begin{array}{l}\text { depth } \\
(\mathrm{m})\end{array}$ & $\begin{array}{l}\text { fracture length } \\
\qquad(\mathrm{cm})\end{array}$ & $\begin{array}{l}\text { fracture opening } \\
(\mathrm{cm})\end{array}$ & $\begin{array}{l}\text { fracture areal density }(\mathrm{cm} / \\
\left.\qquad \mathrm{cm}^{2}\right)\end{array}$ & $\begin{array}{l}\text { fracture permeability } \\
(\mathrm{mD})\end{array}$ & $\begin{array}{l}\text { fracture porosity } \\
(\%)\end{array}$ \\
\hline 1 & L104 & 6282 & 0.6 & 6.3 & 0.4 & 0.50 & 1.04 \\
\hline 2 & $\mathrm{~L} 17$ & 5816 & 1.8 & 12.0 & 0.4 & 2.63 & 1.09 \\
\hline 3 & & 5855 & 0.1 & 13.7 & 0.1 & 9.06 & 2.55 \\
\hline 4 & L004-x1 & 6166 & 0.4 & 19.6 & 0.8 & 34.81 & 5.60 \\
\hline 5 & & 6167 & 1.0 & 12.3 & 0.8 & 10.17 & 2.23 \\
\hline 6 & & 6178 & 0.4 & 36.6 & 0.3 & 16.94 & 3.36 \\
\hline 7 & L4 & 6000 & 3.0 & 4.8 & 0.6 & 2.38 & 2.20 \\
\hline 8 & & 6001 & 2.8 & 14.8 & 0.7 & 5.90 & 5.12 \\
\hline 9 & L16 & 5976 & 3.8 & 25.6 & 1.3 & 46.85 & 3.72 \\
\hline 10 & & 5978 & 2.1 & 22.4 & 0.7 & 15.66 & 5.82 \\
\hline 11 & & 5981 & 2.3 & 19.8 & 1.1 & 14.56 & 6.33 \\
\hline 12 & & 5988 & 2.1 & 18.6 & 0.8 & 13.29 & 4.01 \\
\hline 11 & LT1 & 5713 & 2.2 & 23.4 & 1.0 & 15.91 & 2.57 \\
\hline 12 & LT2 & 5855 & 2.8 & 29.2 & 1.6 & 36.68 & 7.25 \\
\hline 13 & LT1 & 6106 & 2.4 & 20.0 & 1.2 & 28.74 & 3.80 \\
\hline 14 & S1 & 5272 & 1.7 & 11.4 & 0.2 & 8.83 & 3.84 \\
\hline 15 & B1 & 5906 & 1.9 & 10.9 & 0.4 & 11.22 & 4.88 \\
\hline
\end{tabular}

length, the opening, the density, the filling degree, and the occurrence of the fractures. According to the extension length, natural fractures can be classified into four types: large-scale fractures $(>20 \mathrm{~cm})$, medium-scale fractures $(10-20 \mathrm{~cm})$, small-scale fractures $(5-10 \mathrm{~cm})$, and microfractures $(<5$ $\mathrm{cm}) .{ }^{9,10}$ The reservoirs of the Maokou Formation are dominated by medium-scale fractures, accounting for about $48 \%$, followed by large-scale fractures, accounting for about $20 \%$ (Figure 6a). It is generally believed that the greater the extension length of the fractures, the better the effect of oil and gas migration and the greater the contribution to the reservoir. The fracture inclination is relatively large, mainly vertical fractures $\left(75-90^{\circ}\right)$ and high-angle fractures $\left(45-75^{\circ}\right)$, and low-angle and horizontal fractures are relatively rare (Figure $6 \mathrm{~b})$. The fracture line density is mainly concentrated in the interval greater than $5 \mathrm{~m}^{-1}$, accounting for $62.5 \%$ of all fracture development sections (Figure 6c). The fracture opening is mainly $1-3 \mathrm{~mm}$, accounting for about $48 \%$ (Figure $6 \mathrm{~d}$ ). Given the filling situation, natural fractures can be divided into unfilled fractures, half-filled fractures, local-filled fractures, and fully filled fractures, and their effectiveness decreases in order. The unfilled and half-filled fractures in the study area accounted for 42 and 24\%, respectively, with excellent effectiveness (Figure 6e). The fillings were mainly calcite and asphalt, with a small amount of argillaceous, dolomite, and quartz (Figure 6f). It should be pointed out that the core fracture parameters do not authentically reflect the actual conditions of down-hole fractures. Still, these parameters are theoretical indicators that quantitatively describe the characteristics of fracture development with statistical significance. Moreover, the thin-slice observation was also conducted to calculate the characteristic parameters of microfractures. The length of the microfractures is between 0.1 and $5.0 \mathrm{~cm}$, the opening is between 0.01 and $0.07 \mathrm{~mm}$, the surface density is between 0.1 and $1.9 \mathrm{~cm} / \mathrm{cm}^{2}$, and the fillings are mainly calcite, asphalt, and mud.

According to the imaging logging interpretation of the five wells (LT1, LT2, L17, L104, and L004-x1), the fracture development azimuths mainly include near-EW $\left(270 \pm 5^{\circ}\right)$, NWW $\left(295 \pm 5^{\circ}\right)$, NNW $\left(335 \pm 5^{\circ}\right)$, near-SN $\left(0 \pm 5^{\circ}\right)$, NW $\left(315 \pm 5^{\circ}\right)$, and NNE $\left(20 \pm 5^{\circ}\right)$ directions, among which the NNE fractures are the most developed (Figure 7 ).

In addition, the response characteristics of conventional logging corresponding to the fracture development section are different, which is the basis of fracture identification using conventional logging. In general, dual-lateral resistivity logging, acoustic logging, and radioactivity logging are mainly used to identify fractures. Dual-lateral resistivity logging has the most obvious response characteristics, and deep and shallow resistivity is usually positive or negative anomalies in the fracture development area. ${ }^{58-60}$ In this paper, seven wells in the study area were identified, and the thickness of the fracture 


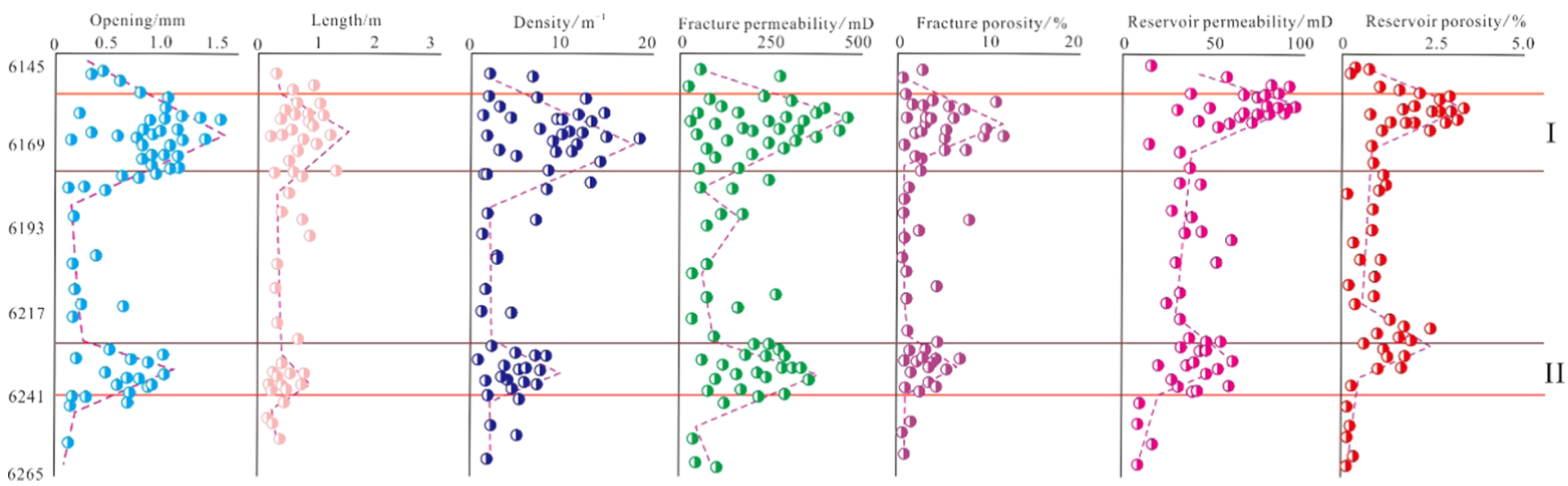

Figure 9. Longitudinal comparison of parameter characteristics of fractures and physical properties of the reservoir of well L004-x1. (a) Fracture opening, (b) fracture length, (c) fracture density, (d) fracture permeability, (e) fracture porosity, (f) reservoir permeability, and (g) reservoir porosity.

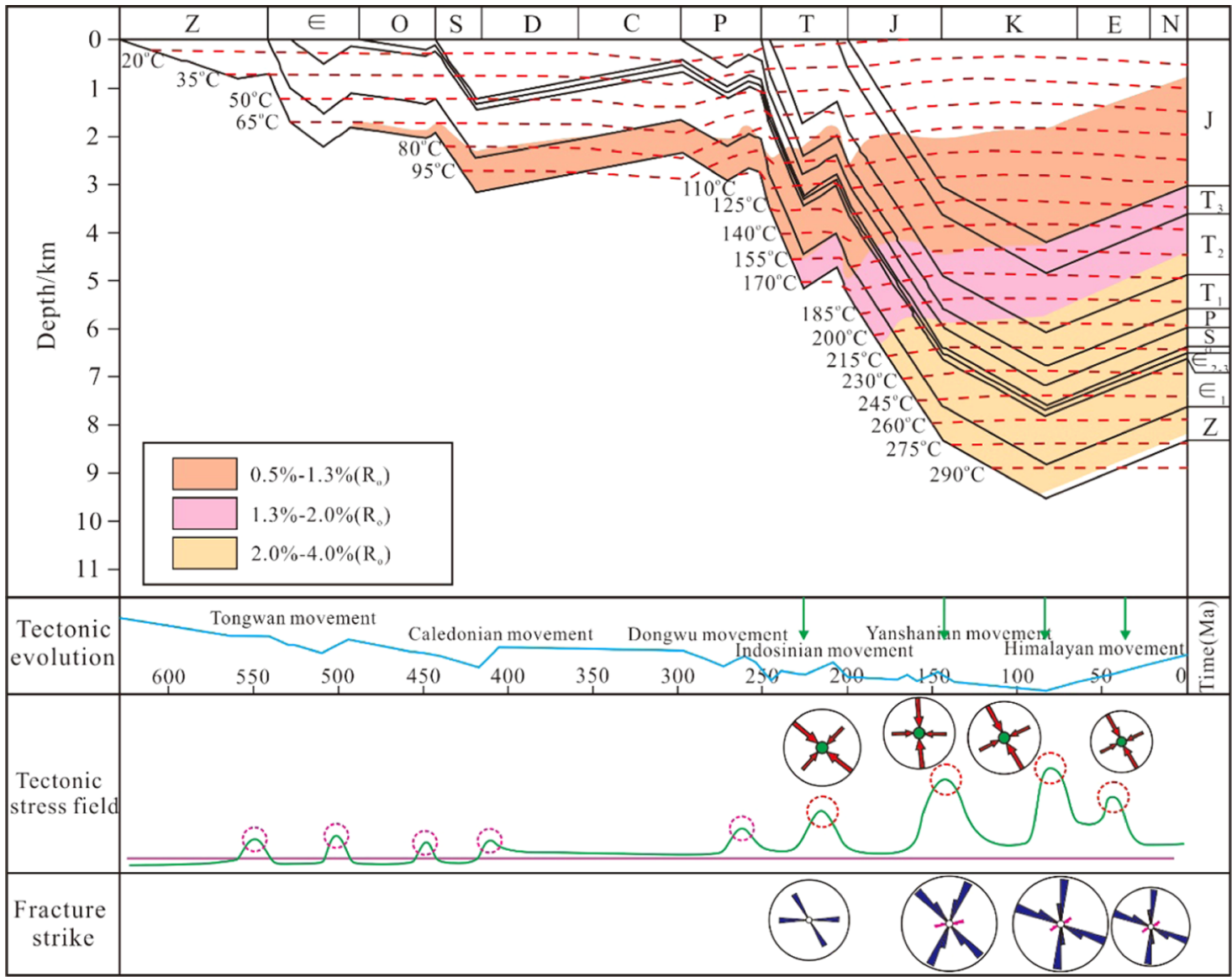

Figure 10. Formation stage and the formation mechanism of the fractures of the Maokou Formation in the study area. ${ }^{1,62}$

development section was counted. For example, the fracture development zone of well L16 mainly includes 5942.8-5945.0, 5948.2-5950.0, 5950.6-5951.3, 5975.5-5976.2, 5960.35962.4 , and 5968.2-5968.9 $\mathrm{m}$, with a total thickness of 8.2 $\mathrm{m}$. The reservoir's average porosity and water saturation are 2.1 and $37.4 \%$, respectively (Figure 8 ). The porosity and permeability of the reservoir at the fracture development section increase significantly, and the permeability is the most obvious. The logging interpretation results are all gas reservoirs.
4.1.3. Physical Parameters of Fractures. Based on the statistical results of the characteristic parameters of the macroand microfractures, physical parameters (porosity and permeability) of the typical wells in the study area were calculated using the Monte Carlo method of multiple approximations, with the results shown in Tables 1 and 2 . The calculation results showed that there are differences in the development degree of fractures at different depths. Taking well L004-xl as an example, it can be found from the changes of fracture parameters (the length, the opening, and the density) of the reservoir and physical properties of the 
Table 3. Average Physical Properties of Macro- and Microfractures and Their Ratio of the Reservoir Physical Properties

$\begin{array}{cccccc}\text { physical parameters } & \text { macrofractures } & \text { microfractures } & \text { reservoir } & \text { the ratio of macrofractures }(\%) & \text { the ratio of microfractures }(\%) \\ \text { porosity } & 0.2 & 4.3 & 1.56 & 12.8 & 276 \\ \text { permeability } & 188.4 & 18.3 & 1.66 & 11349 & 1102\end{array}$

fractures with depths that as the depth increases, the fracture parameters and physical property parameters have the same changing law. Each parameter shows two obvious abnormally high-value bands, which correspond to 6158-6178 $\mathrm{m}$ (I) and 6230-6240 m (II), respectively (Figure 9). The fracture parameters of the two developed sections are higher than those of other depths. The parameters of section I of a shallower depth are higher than those of section II. On the whole, the development degree of fractures decreases with the increase in the depth.

Based on the contrast between the physical parameters of the fractures and the vertical distribution rule of those of the reservoir, it can be seen that the changing trend of the distribution law of physical properties of the fractured reservoir with the change in the depth is consistent with that of fracture parameters (Figure 9). In general, the physical properties of the reservoir are also divided into two abnormally high-value zones, which correspond to the abnormal development zones of I and II, respectively. The difference value of the high-value zone of physical properties of shallower reservoirs is greater than that of deeper reservoirs, which is similar to the longitudinal development law of fractures. With the increase in the depth, the physical parameters of the reservoir decrease, which is related to the compaction action of the formation. However, if the fractures are well developed, the physical properties of the reservoir will have abnormally high-value zones. This is one of the reasons for the high production of well L004-x1 in the corresponding depth.

4.2. Formation Mechanism of Natural Fractures. The development degree and the orientation of natural fractures are controlled by tectonic stress. The magnitude and the direction of tectonic stress differ in different stages of tectonic evolution. According to the matching relationship between the fracture strike and the structural stage, the formation stage of the fractures can be identified. ${ }^{1,9,10,61}$ The comprehensive regional tectonic evolution, the intersecting relationship of core fractures, the burial-thermal evolution history, and previous research results show that the Maokou Formation in the study area has undergone at least three stages of tectonic movement after its formation. The corresponding fracture formation stage also refers to at least three: the Indosinian tectonic movement stage (232-210 Ma), the early-mid Yanshanian tectonic movement (145-90 Ma) stage, and the late Yanshanian tectonic movement-the Himalayan tectonic movement stage (90-0 Ma), respectively (Figure 10). 1,62-66

Therefore, during the Indosinian tectonic movement stage, the study area was mainly affected by the compression and overthrow of the Longmenshan orogenic belt from NW to SE, creating the embryonic form of the NE directional structure in the JLS area. ${ }^{67-69}$ Generally, the structural principle stress direction is parallel to the acute bisector of the $\mathrm{X}$-shaped conjugate shear fracture. Therefore, during this stage, the plane shear fractures of NW and NEE directions were mainly formed in the study area, and this set of fractures intersect with the layer at a high angle. In the early-mid Yanshanian tectonic movement stage, the study area was strongly compressed from north to south. Thus, the plane shear fractures of NNE and
NW directions were formed, along with a few section shear fractures in the near-EW direction parallel to the principal stress direction. Late Yanshanian tectonic movement-the Himalayan tectonic movement stage was mainly affected by the Longmenshan and Micangshan orogenic belts, which gave birth to a joint force of the NNW direction, having NWW and near-SN directional plane shear fractures and the $\mathrm{NE}$ directional section shear fractures in the Maokou Formation (Figure 10). Under the continuous action of tectonic stress in the Himalayan stage, the current fracture and fault system was formed in the study area, and the JLS structure was finally finalized.

\section{DISCUSSION}

5.1. Quantitative Relationship between Fracture Characteristics and Physical Properties of the Reservoirs. The physical properties of macro- and microfractures were calculated with the Monte Carlo approximation method (Tables 1 and 2). The average values were compared with the physical properties of the reservoir. The average porosity of the Maokou Formation reservoir in the study area is $1.56 \%$, and the average permeability is $1.88 \mathrm{mD}$. The average porosity of macrofractures is $0.2 \%$, with a contribution rate of $12.8 \%$ to the porosity of the reservoir, but the average permeability is 188.4 $\mathrm{mD}$, with a very large contribution rate of $11349 \%$ to the permeability of the reservoir. The average porosity of microfractures is $4.3 \%$, with a contribution rate of $276 \%$ to the porosity of the reservoir, and the average permeability is $18.3 \mathrm{mD}$, with a contribution rate of $1102 \%$ (Table 3 ). Therefore, both macro- and microfractures have a greater contribution to reservoir permeability, and the microfractures effectively increase the reservoir's porosity.

By comparing the measured physical properties data, there are noticeable differences in the porosity and permeability correlation of samples without the fractures, samples with macrofractures, and samples with microfractures (Figure 11), and the differences are mainly manifested below. (1) The porosity and permeability data of samples without fractures show a good linear relationship, demonstrating the physical characteristics of conventional reservoirs. (2) The porosity and permeability relationship curve of macrofractures lies at the

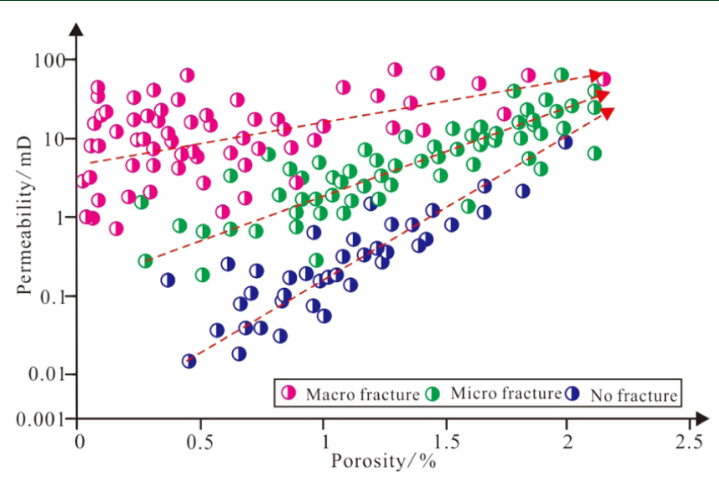

Figure 11. Comparison diagram of porosity and permeability intersection of Maokou Formation reservoirs in the study area. 

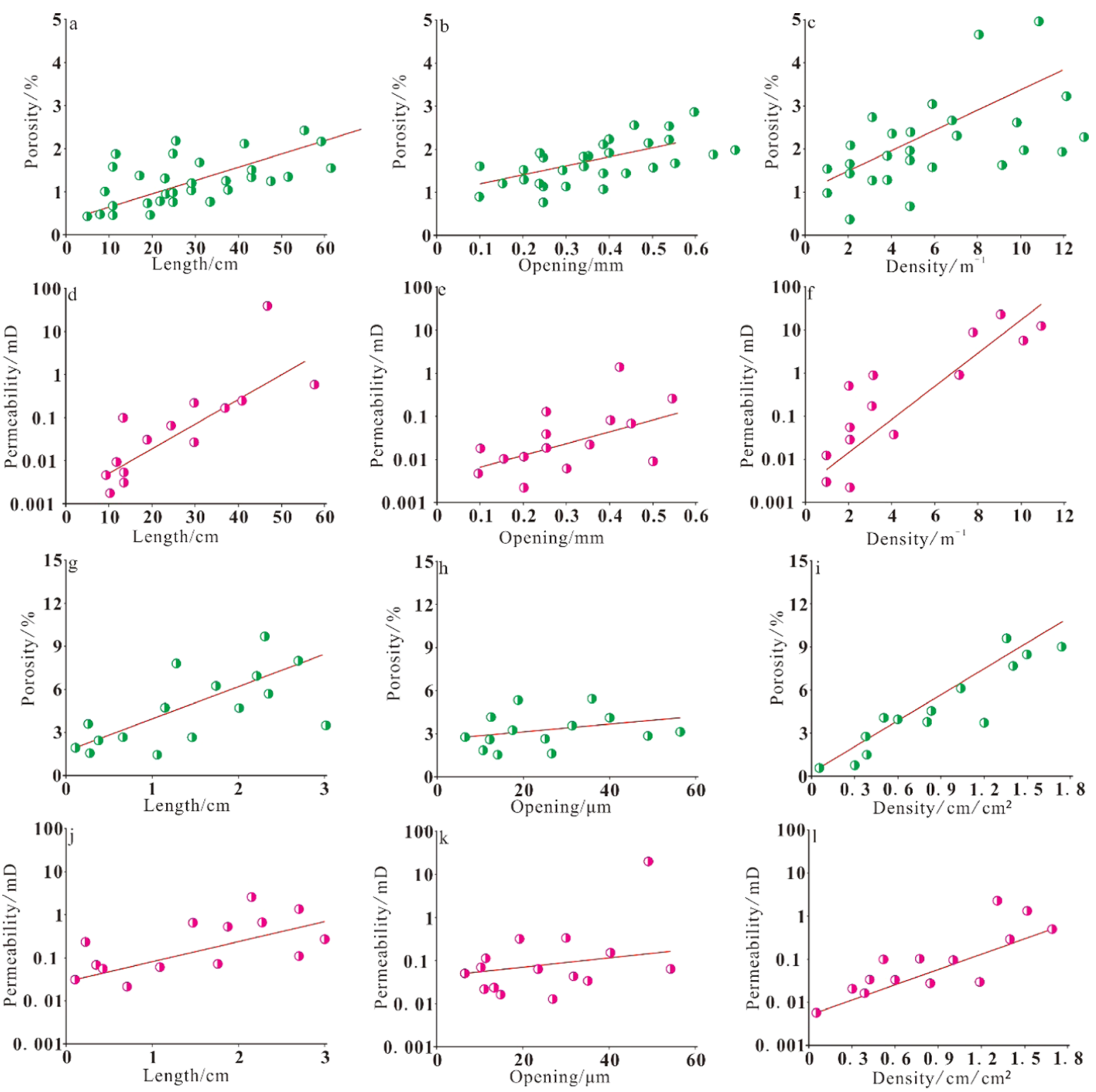

Figure 12. Relationship between the fracture development characteristics (length, opening, and density) and the physical properties (porosity and permeability) of the reservoir in the Maokou Formation reservoir in the study area. (a) - (f) Macrofractures and (g) $-(\mathrm{l})$ microfractures.

top, indicating that macrofractures greatly influence the permeability of the reservoir. When the porosity is low, the existence of fractures can significantly improve the permeability of the reservoir. (3) The porosity and permeability relationship curve of microfractures lies between the first two, implying that they can improve the permeability of the reservoir but in a smaller manner than macrofractures. Meanwhile, they can also increase the permeability porosity of the reservoir. (4) As the physical properties of the reservoir get better, the effect of the fractures in improving the physical properties of the reservoir becomes relatively weakened. When the porosity of the reservoir exceeds $2.2 \%$, the three types of curves gradually overlap and the fractures affect hardly.

To further analyze the impact mechanism of macro- and microfractures on the physical properties of the reservoir, the length, the opening, the linear density, the areal density, and other parameters of macrofractures and microfractures were fitted with porosity and permeability, respectively. Thus, a quantitative relationship model among them was established. It can be known as follows through comparison and analysis of the results (Figure 12). (1) Various parameters of macrofractures are positively correlated with the physical properties of the reservoir to varying degrees, which shows that macrofractures have a positive and effective effect on the improvement of the physical properties of the reservoir. However, different fracture characteristic parameters show different degrees of correlation with and physical properties of the reservoir. The influence degree of each parameter on reservoir physical properties from small to big is the opening, the length, and the linear density. The permeability has a greater correlation with the characteristic parameters of macrofractures than the porosity, indicating that macrofractures can better improve reservoir permeability (Figure 12a-f). (2) Compared with macrofractures, the characteristic parameters of microfractures have a poor correlation with the physical properties of the reservoir, but the general relationship 
is still positive. The microfractures still play a certain role in improving the physical properties of the reservoir, but they have a weaker impact than macrofractures and a small effect on the permeability of the reservoir (Figure $12 \mathrm{~g}-1$ ). The order of the influence significance of each parameter on the physical properties from small to big is the opening, the length, and the areal density.

In summary, the fractures have a positive effect on the physical properties of the reservoir, and they have the closest relationship with the linear and areal density of the fractures, followed by the length and opening. The fractures have impacts on the reservoir, mainly manifested in the following three aspects. (1) The fractures can be used as channels for oil and gas migration to increase the permeability of the reservoir and affect the enrichment of oil and gas, (2) the fractures and pores formed by karstification can be used as effective storage space to increase the overall porosity of the reservoir, and (3) the fractures provide passages for fluid activity to facilitate dissolution of the reservoir to form the secondary pores, and meanwhile, groundwater can increase the brittle minerals of the rock and help to form new fractures. Combined with the development and distribution characteristics of various fracture types, tectonic fractures generally play a role in the seepage of the reservoir (especially the high-angle shear fractures), thanks to the large opening and long extension. Microfractures can increase the connectivity among pores and act as matrix pores, which can improve the physical properties of the reservoir to some extent. ${ }^{70,71}$ These fractures of different scales intersect each other and connect the pores and caves, construct a complex system of pores, caves, and fractures, facilitating the migration, accumulation, and high yield of oil and gas.

5.2. Effect of Fracture Development on Productivity. 5.2.1. Relationship Between Fracture Development Characteristic Parameters and the Productivity Index. The productivity index refers to the gas production per $1 \mathrm{~m}$ interval under unit pressure difference. ${ }^{1,73}$ According to the production data of 10 wells, such as the wells L17, L16, and LT1, the productivity index increases significantly with the increase in the fracture dip angle, length, and density, showing a good positive correlation (Figure 13). Generally, a fracture dip affects the size of the opening. When the horizontal fracture is under the static rock pressure of the overlying strata, the opening is small or even completely closed, which has little effect on the gas productivity. ${ }^{74,75}$ The opening of high-angle fracture and oblique fracture is larger, and the permeability is better (Figure 13a). The denser the fractures, the higher the productivity index under the same pressure difference and production system (Figure 13b). The larger the fracture length, the longer the fracture cuts the borehole, the higher the gas production per unit interval (Figure 13c).

5.2.2. Relationship between Fracture Development and Productivity. Fracture development has an important influence on the reservoir's oil-bearing properties and physical properties, and the two determine the reservoir's properties and the production capability of oil and gas. ${ }^{76-78}$ According to the statistical analysis of the testing results with developed fractures in the study area, the gas layers in the reservoir accounted for $47 \%$, and the reservoirs with productivity accounted for $98.2 \%$ (Figure 14a). Additionally, statistics on the average values of fracture porosity parameters corresponding to the dry layer, the water layer, and the gas layer show that the average fracture porosity of the gas layer is the highest of $2.03 \%$. In comparison, that of the dry layer is only $0.76 \%$
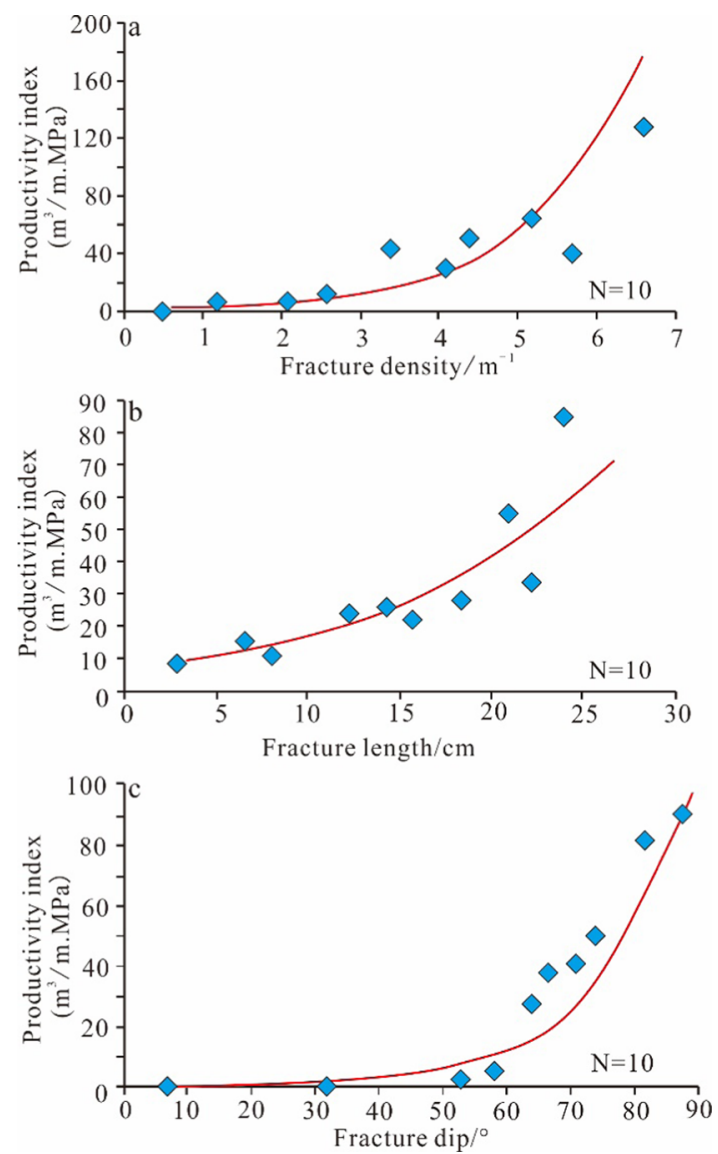

Figure 13. Relationship between fracture characteristic parameters and the productivity index. (a) Fracture density, (b) fracture length, and (c) fracture dip.

(Figure 14b). The difference in average porosity of the fractures between the gas layer and the water layer is relatively small, and both are much higher than that of the dry layer, indicating that the higher the degree of fracture development, the greater the probability that the reservoir is effective (the gas layer).

Based on the observation of the cores, thin slices, and logging interpretation, it can be seen that the dissolved pore zone or cave is often born with fractures. ${ }^{79,80}$ The fractures improve the gas production effect of the reservoir by communicating a large number of pores and caves. Based on the statistics of fracture porosity and single-well production in some reservoirs of the Maokou Formation, there is a remarkable positive correlation between fracture development and single-well productivity, and the single-well productivity increases exponentially with the increase in fracture porosity (Figure 15). When the average fracture porosity is less than $1.2 \%$, the single-well productivity changes with the increase in fracture porosity. That is, the output is hardly affected by fractures. When the average fracture porosity is greater than $1.2 \%$, the positive correlation is noticeable, and the daily test output increases exponentially. Therefore, a fracture porosity of $1.2 \%$ can be used as the limit of the division of the properties of fractured reservoirs. It is still to be pointed out that since many factors can affect oil and gas production, the physical properties of fractures show no absolute positive correlation with productivity. However, they are still one of the most important influencing factors. According to logging 

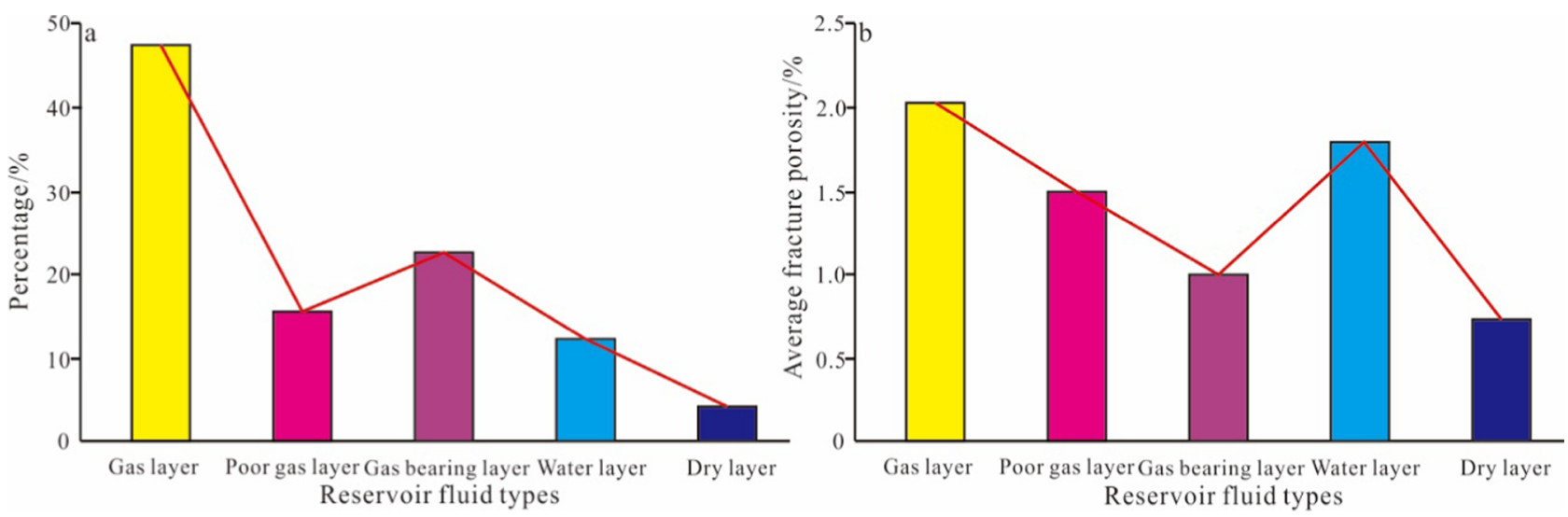

Figure 14. Relationship between the fractures and reservoir characteristics of the Maokou Formation in the study area. (a) Fluid types of fractured reservoirs and (b) relationship between average fracture porosity and reservoir fluid types.

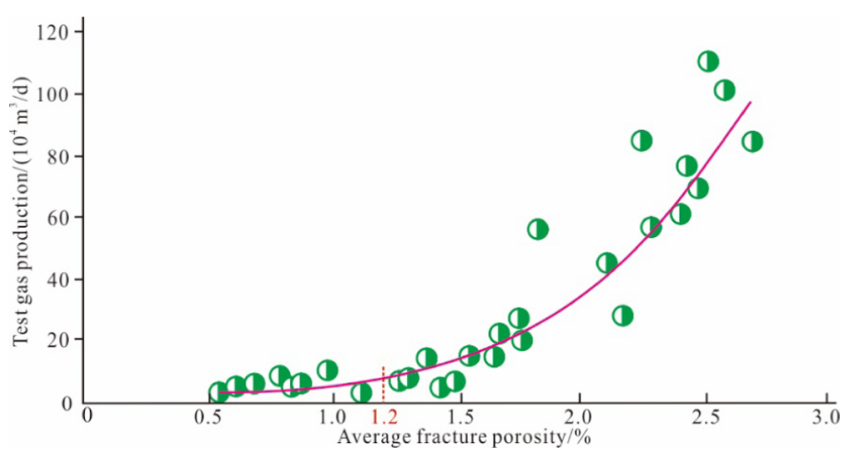

Figure 15. Relationship between fracture porosity and gas productivity of the Maokou Formation in the study area.

interpretation results of the seven typical wells, fracture development has an obvious control effect on productivity. In this study, the degree of fracture development per unit interval of seven wells in the study area was statistically analyzed. The thickness of fracture development also showed an obvious positive correlation with reservoir productivity (Figure 16).

\section{CONCLUSIONS}

The development of natural fractures (macro- and microfractures) of the Maokou Formation in the JLS area is relatively significant. Shear fracture formed by the action of tectonics is the major type, tension fractures are rarely seen,

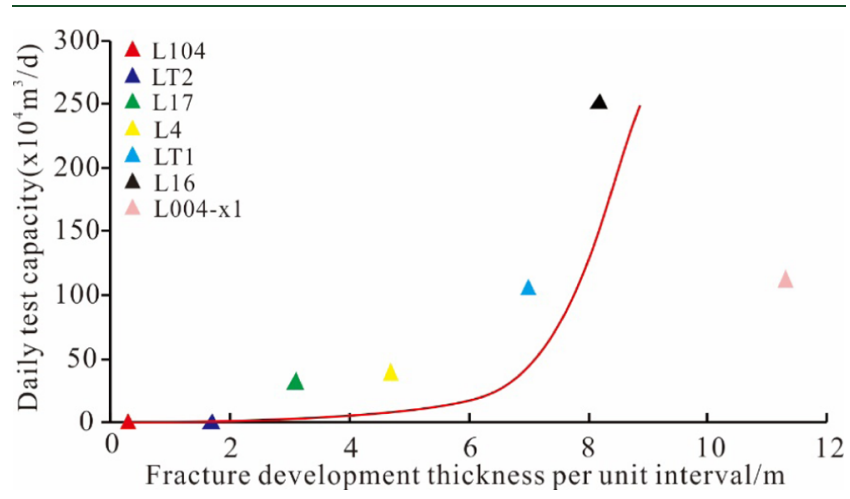

Figure 16. Relationship between longitudinal fracture thickness and productivity. and dissolution fractures are the major diagenetic fractures. The fractures are characterized by a medium development scale $(10-20 \mathrm{~cm})$, a large dip angle $\left(45-90^{\circ}\right)$, a high density (greater than $5 \mathrm{~m}^{-1}$ ), a medium opening $(1-3 \mathrm{~mm}$ ), a low filling degree (mainly unfilled), the major filling of calcite, and so on. The fracture strikes are mostly NNE, NW, and near-EW directions. There are three main formation stages of natural fractures: the Indosinian tectonic movement stage (232-210 $\mathrm{Ma}$ ), the early-mid Yanshanian tectonic movement (145-90 $\mathrm{Ma})$, and the late Yanshanian-the Himalayan tectonic movement stage (90-0 Ma).

With the Monte Carlo probability and statistics method, the characteristic parameters of fracture development were quantitatively evaluated and analyzed. Both the fracture parameters and physical property parameters show two obvious abnormally high-value zones. The reservoir physical properties of the fracture-developed section are significantly higher than those of sections of other depths, and fracture development degree decreases with the increase in the depth. The characteristic parameters of macro- and microfractures are positively correlated with the physical properties of the reservoir. The sequence of the influence extent of each parameter on the physical properties of the reservoir is as follows: the opening $<$ the length $<$ the linear density (areal density).

The fractures can be used as storage space and migration channels for oil and gas, which play an important role in improving the reservoir's physical properties, oil content, and productivity. Macrofractures mainly improve the permeability of the reservoir and play the role of transporting oil and gas. Microfractures, as an important storage space of the reservoir mainly increase the porosity of the reservoir. The degree of fracture development is closely related to the fluid nature of the reservoir, and meanwhile has an obvious positive correlation with productivity. The average fracture porosity of $1.2 \%$ can be used as the boundary for the division of the reservoir nature.

\section{AUTHOR INFORMATION}

\section{Corresponding Authors}

Hu Li - Sichuan College of Architectural Technology, Chengdu, Sichuan 610399, People's Republic of China; School of Geoscience and Technology, Southwest Petroleum University, Chengdu, Sichuan 610500, People's Republic of 
China; 이이이.org/0000-0003-1153-1467;

Email: lihu860628@126.com

Qirong Qin - School of Geoscience and Technology, Southwest Petroleum University, Chengdu, Sichuan 610500, People's

Republic of China; Email: Qin-349274410@qq.com

\section{Authors}

Qin Wang - Sichuan College of Architectural Technology, Chengdu, Sichuan 610399, People's Republic of China

Xinyu Ge - School of Geoscience and Technology, Southwest Petroleum University, Chengdu, Sichuan 610500, People's Republic of China

Complete contact information is available at:

https://pubs.acs.org/10.1021/acs.energyfuels.1c01581

\section{Notes}

The authors declare no competing financial interest.

\section{ACKNOWLEDGMENTS}

The authors are grateful to Northwest Oil and Gas Field of Southwest Oil \& Gas Field Company, PetroChina, for their kind help and support in completing this study. They also thank all of the editors and reviewers for their helpful comments and suggestions.

\section{REFERENCES}

(1) Li, H.; Qin, Q. R.; Zhang, B. J.; Ge, X. Y.; Hu, X.; Fan, C. H.; Tang, H. M. Tectonic fracture formation and distribution in ultradeep marine carbonate gas reservoirs: A case study of the Maokou Formation in the Jiulongshan gas field, Sichuan Basin, Southwest China. Energy Fuels 2020, 34, 14132-14146.

(2) Méndez, J. N.; Jin, Q.; González, M.; Zhang, X. D.; Lobo, C.; Boateng, C. D.; Zambrano, M. Fracture characterization and modeling of karsted carbonate reservoirs: A case study in Tahe oilfield, Tarim Basin (western China). Mar. Pet. Geol. 2020, 112, No. 104104.

(3) Zhang, K.; Jia, C. Z.; Song, Y.; Jiang, S.; Jiang, Z. X.; Wen, M.; Huang, Y. Z.; Liu, X. X.; Jiang, T.; Peng, J.; Wang, X.; Xia, Q. S.; Li, B.; Li, X.; Liu, T. L. Analysis of Lower Cambrian shale gas composition, source, and accumulation pattern in different tectonic backgrounds: A case study of Weiyuan Block in the Upper Yangtze region and Xiuwu Basin in the Lower Yangtze region. Fuel 2020, 263, No. 115978.

(4) Wang, L.; He, Y. M.; Peng, X.; Deng, H.; Liu, Y. C.; Xu, W. Pore structure characteristics of an ultradeep carbonate gas reservoir and their effects on gas storage and percolation capacities in the Deng IV member, Gaoshiti-Moxi Area, Sichuan Basin, SW China. Mar. Pet. Geol. 2020, 111, 44-65.

(5) Kang, H. P.; Xu, G.; Wang, B. M.; Wu, Y. Z.; Jiang, P. F.; Pan, J. F.; Ren, H. W.; Zhang, Y. J.; Pang, Y. H. Forty years development and prospects of underground coal mining and strata control technologies in China. J. Min. Strata Control Eng. 2019, 1, No. 013501.

(6) Li, L. F.; Zhang, X. H.; Deng, H. L.; Han, L. P. Mechanical properties and energy evolution of sandstone subjected to uniaxial compression with different loading rates. J. Min. Strata Control Eng. 2020, 2, No. 043037.

(7) Chen, G. B.; Li, T.; Yang, L.; Zhang, G. H.; Li, J. W.; Dong, G. $\mathrm{H}$. Mechanical properties and failure mechanism of combined bodies with different coal-rock ratios and combinations. J. Min. Strata Control Eng. 2021, 3, No. 023522.

(8) Fan, C. H.; He, S.; Zhang, Y.; Qin, Q. R.; Zhong, C. Development phases and mechanisms of tectonic fractures in the Longmaxi Formation shale of the Dingshan area in southeast Sichuan Basin, China. Acta Geol. Sin. (Engl. Ed.) 2018, 92, 2351-2366.

(9) Fan, C. H.; Li, H.; Zhao, S. X.; Qin, Q. R.; Fan, Y.; Wu, J. F.; Zhang, J. Formation stages and evolution patterns of structural fractures in marine shale: A case study of the Lower Silurian Longmaxi Formation in the Changning area of the southern Sichuan Basin, China. Energy Fuels 2020, 34, 9524-9539.

(10) Li, H.; Tang, H. M.; Qin, Q. R.; Zhou, J. L.; Qin, Z. J.; Fan, C. H.; Su, P. D.; Wang, Q.; Zhong, C. Characteristics, formation stages, and genetic mechanisms of tectonic fractures in the tight gas sandstones reservoir: A case study of Xujiahe Formation in YB area, Sichuan Basin, China. J. Pet. Sci. Eng. 2019, 178, 723-735.

(11) Wang, D. L.; Hao, B. Y.; Liang, X. M. Slurry diffusion of single fracture based on fluid-solid coupling. J. Min. Strata Control Eng. 2021, 3, No. 013038.

(12) Zhao, K. K.; Jiang, P. F.; Feng, Yj.; Sun, X. D.; Cheng, L. X.; Zheng, J. W. Investigation of the characteristics of hydraulic fracture initiation by using maximum tangential stress criterion. J. Min. Strata Control Eng. 2020, 3, No. 023520.

(13) Gong, L.; Su, X. C.; Gao, S.; Fu, X. F.; Jabbari, H.; Wang, X. X.; Liu, B.; Yue, W. T.; Wang, Z. S.; Gao, A. Characteristics and formation mechanism of natural fractures in the tight gas sandstones of Jiulongshan gas field, China. J. Pet. Sci. Eng. 2019, 175, 1112-1121.

(14) Zeng, L. B.; Jiang, J. W.; Yang, Y. L. Fractures in the low porosity and ultra-low permeability glutenite reservoirs: a case study of the late Eocene Hetaoyuan formation in the Anpeng Oilfield, Nanxiang Basin, China. Mar. Pet. Geol. 2010, 27, 1642-1650.

(15) Chen, S. D.; Liu, P. C.; Tang, D. Z.; Tao, S.; Zhang, T. Y. Identification of thin layer coal texture using geophysical logging data: Investigation by wavelet transform and linear discrimination analysis. Int. J. Coal Geol. 2021, 239, No. 103727.

(16) Chen, S. D.; Tang, D. Z.; Tao, S.; Liu, P. C.; Jonathan, P. M. Implications of the in situ stress distribution for coalbed methane zonation and hydraulic fracturing in multiple seams, western Guizhou, China. J. Pet. Sci. Eng. 2021, 204, No. 108755.

(17) Liu, J. S.; Yang, H. M.; Wu, X. F.; Liu, Y. The in situ stress field and microscale controlling factors in the Ordos Basin, central China. Int. J. Rock Mech. Min. Sci. 2020, 135, No. 104488.

(18) Liu, J. S.; Yang, H. M.; Bai, J. P.; Wu, K. Y.; Zhang, G. J.; Liu, Y.; Xiao, Z. K. Numerical simulation to determine the fracture aperture in a typical basin of China. Fuel 2021, 283, No. 118952.

(19) Chen, S. D.; Tao, S.; Tian, W. G.; Tang, D. Z.; Zhang, B.; Liu, P. C. Hydrogeological control on the accumulation and production of coalbed methane in the Anze Block, southern Qinshui Basin, China. J. Pet. Sci. Eng. 2021, 198, No. 108138.

(20) Xia, Y. X.; Lu, C.; Yang, G. Y.; Su, S. J.; Pang, L. N.; Ding, G. L.; $\mathrm{Su}, \mathrm{B}$. Experimental study on axial fracture cutting and fracturing of abrasive jet in hard roof hole. J. Min. Strata Control Eng. 2020, 2, No. 033522.

(21) Fan, C. H.; Li, H.; Qin, Q. R.; He, S.; Zhong, C. Geological conditions and exploration potential of shale gas reservoir in Wufeng and Longmaxi Formation of southeastern Sichuan Basin, China. J. Pet. Sci. Eng. 2020, 191, No. 107138.

(22) Gong, L.; Fu, X. F.; Gao, S.; Zhao, P. Q.; Luo, Q. Y.; Zeng, L. B.; Yue, W. T.; Zhang, B. J.; Liu, B. Characterization and prediction of complex natural fractures in the tight conglomerate reservoirs: A fractal method. Energies 2018, 11, 2311.

(23) Ju, W.; Sun, W. F. Tectonic fractures in the lower cretaceous Xiagou formation of Qingxi oilfield, Jiuxi basin, NW China part one: characteristics and controlling factors. J. Pet. Sci. Eng. 2016, 146, 617625 .

(24) Lai, J.; Chen, K. J.; Xin, Y.; Wu, X. N.; Chen, X.; Yang, K. F.; Song, Q. Q.; Wang, G. W.; Ding, X. J. Fracture characterization and detection in the deep Cambrian dolostones in the Tarim Basin, China: Insights from borehole image and sonic logs. J. Pet. Sci. Eng. 2021, 196, No. 107659.

(25) Hou, E. K.; Cong, T.; Xie, X. S.; Wei, J. B. Ground surface fracture development characteristics of shallow double coal seam staggered mining based on particle flow. J. Min. Strata Control Eng. 2020, 2, No. 013521.

(26) Wang, J.; Wang, X. L. Seepage characteristic and fracture development of protected seam caused by mining protecting strata. J. Min. Strata Control Eng. 2021, 3, No. 033511. 
(27) Zhang, C.; Song, W. D.; Fu, J. X.; Li, Y.; Zhang, K. C. Technology for roadway management of fractured rock masses in a submarine gold mine. J. Min. Strata Control Eng. 2020, 2, No. 033039. (28) Zuo, J. P.; Yu, M. L.; Hu, S. Y.; Song, H. Q.; Wei, X.; Shi, Y.; Zuo, S. H. Experimental investigation on fracture mode of different thick rock strata. J. Min. Strata Control Eng. 2019, 1, No. 013007.

(29) Xu, M. H.; Fu, J. Y.; Yang, X.; Liu, J. H.; Wang, Y. F. Seismic detection of the pore and fracture zones in ultradeep carbonate reservoirs in the northwestern Sichuan Basin. Nat. Gas Ind. 2019, 39, $18-24$.

(30) Zhang, B. J.; Xie, J. R.; Yin, H.; Hu, X.; Wang, Y. F.; Yang, X.; Pei, S. Q. Characteristics and exploration direction of the MiddlePermian carbonate reservoirs in the Longmenshan mountain areas, western Sichuan Basin. Nat. Gas Ind. 2018, 38, 33-42.

(31) Bagherzadeh, P.; Goshtasbi, K.; Kazemzadeh, E. Stressdependence of the permeability, porosity, and compressibility of fractured carbonate rock. J. Porous Media 2021, 24, 21-45.

(32) Ponomarev, A. N.; Barabashko, M. S.; Rezvanova, A. E.; Evtushenko, E. P. Influence of Porosity on Fracture Toughness of Hydroxyapatite/Multi-Walled Carbon Nanotubes Biocomposite Materials. Russ. Phys. J. 2021, 63, 1885-1990.

(33) Cai, M. F. Key theories and technologies for surrounding rock stability and ground control in deep mining. J. Min. Strata Control Eng. 2020, 2, No. 033037.

(34) Chen, S. L.; Huang, B. X.; Li, D.; Zhao, X. L.; Xu, J.; Wang, C. W. Experiment study on the basic law of high pressure abrasive hydraulic cutting for coal-rock mass. J. Min. Strata Control Eng. 2020, 2, No. 047521.

(35) Jiang, Y. X.; Tan, X. F.; Zhang, C. J.; Jiang, W.; Wang, J.; Luo, L.; Tan, D. P.; Wang, W.; Xiong, Z. F. Genesis of dolomite in middle Permian Maokou Formation in eastern Sichuan: constraints from in situ geochemistry, sr-mg isotopes, and fluid inclusions. Geofluids 2021, No. 6611140.

(36) Zhong, Y.; Yang, Y. M.; Wen, L.; Luo, B.; Xiao, D.; Li, M. L.; Chen, C.; Zhao, L. K.; Lu, F. F.; Tan, X. C. Reconstruction and petroleum geological significance of lithofacies paleogeography and paleokarst geomorphology of the middle Permian Maokou Formation in northwestern Sichuan Basin, Sw China. Pet. Explor. Dev. 2021, 48, 95-109.

(37) Liu, Y. X.; Gao, M. S.; Zhao, H. S.; He, S. L.; Li, Z. G.; Zhang, Z. C. Detection of overlying rock structure and identification of key stratum by drilling and logging technology. J. Min. Strata Control Eng. 2020, 2, No. 023038.

(38) Qie, L.; Shi, Y. N.; Liu, J. G. Experimental study on grouting diffusion of gangue solid filling bulk materials. J. Min. Strata Control Eng. 2021, 3, No. 023011.

(39) Zhang, W.; Wu, T.; Li, Z. P.; Liu, S. Y.; Qiu, A. O.; Li, Y. J.; Shi, Y. B. Fracture recognition in ultrasonic logging images via unsupervised segmentation network. Earth Sci. Inform. 2021, 14, 955-964.

(40) Shafiabadi, M.; Kamkar-Rouhani, A.; Riabi, S. R. G.; Kahoo, A. R.; Tokhmechi, B. Identification of reservoir fractures on FMI image logs using Canny and Sobel edge detection algorithms. Oil Gas Sci. Technol. 2021, 76, 10.

(41) Zeng, W. T.; Zhang, J. C.; Ding, W. L.; Zhao, S.; Zhang, Y. Q.; Liu, Z. J.; Jiu, K. Fracture development in Paleozoic shale of Chongqing area (South China). Part one: fracture characteristics and comparative analysis of main controlling factors. J. Asian Earth Sci. 2013, 75, 251-266.

(42) Tabatabaei, H. Analysis of fracture density and their effect on mud loss in Asmari reservoir via FMI/ FMS log, Rag-e-Safid oil field, SW of Iran. Himal. Geol. 2021, 42, 205-210.

(43) Wang, Y.; Tu, M.; Fu, B. J.; Bu, Q. W. Lateral mining-induced stress distributive property of deep mining and gob-side entry support. J. Min. Strata Control Eng. 2020, 2, No. 033012.

(44) Sheng, Y. N.; Li, W. T.; Jiang, J. B.; Lan, K.; Kong, H.; Yan, Y. P. Quantitative characterization of collapse and fracture pressure uncertainty based on Monte Carlo simulation. J. Pet. Explor. Prod. 2021, 2199.
(45) Elfarra, M. A.; Kaya, M. Estimation of electricity cost of wind energy using Monte Carlo simulations based on nonparametric and parametric probability density functions. Alexandria Eng. J. 2021, 60, $3631-3640$

(46) Cheimarios, N.; To, D.; Kokkoris, G.; Memos, G.; Boudouvis, A. G. Monte carlo and kinetic monte carlo models for deposition processes: a review of recent works. Front. Phys. 2021, 9, No. 631918.

(47) Krauth, W. Event-chain Monte Carlo: foundations, applications, and prospects. Front. Phys. 2021, 9, No. 663457.

(48) Mitus, A. C.; Saphiannikova, M.; Radosz, W.; Toshchevikov, V.; Pawlik, G. Modeling of nonlinear optical phenomena in host-guest systems using bond fluctuation Monte Carlo model: a review. Materials 2021, 14, 1454.

(49) Liu, Z. S.; Zhang, P.; Ma, D. Q. Reliability analysis of saturated sand liquefaction based on Monte Carlo method. Bull. Sci. Technol. 2020, 36, 87-91.

(50) Ragi, S.; Mittelmann, H. D. Random-sampling Monte-Carlo tree search methods for cost approximation in long-horizon optimal control. IEEE Control Syst. Lett. 2021, 5, 1759-1764.

(51) Chai, J.; Ouyang, Y. B.; Zhang, D. D. Crackdetection method in similar material models based on DIC. J. Min. Strata Control Eng. 2020, 2, No. 023015

(52) Yin, S.; Han, C.; Wu, Z.; Li, Q. Developmental characteristics, influencing factors, and prediction of fractures for a tight gas sandstone in a gentle structural area of the Ordos Basin, China. J. Nat. Gas Sci. Eng. 2019, 72, No. 103032.

(53) Yin, S.; Wu, Z. H. Geomechanical simulation of low-order fracture of tight sandstone. Mar. Pet. Geol.. 2020, 117, No. 104359.

(54) Xu, N. Z.; Gao, C. Study on the special rules of surface subsidence affected by normal faults. J. Min. Strata Control Eng. 2020, 2, No. 011007.

(55) Liu, J. S.; Ding, W. L.; Wang, R. Y.; Yin, S.; Yang, H. M.; Gu, Y. Simulation of paleotectonic stress fields and quantitative prediction of multi-period fractures in shale reservoirs: a case study of the Niutitang Formation in the Lower Cambrian in the Cen'gong block, South China. Mar. Pet. Geol. 2017, 84, 289-310.

(56) $\mathrm{Bu}, \mathrm{T}$. T. Dynamic response relationship between roof movement and deformation of roadway in fully mechanized caving face of deep and thick coal seam. J. Min. Strata Control Eng. 2021, 3, No. 023031

(57) Zeng, L. B. Microfracturing in the Upper Triassic Sichuan Basin tight-gas sandstones: Tectonic, overpressure, and diagenetic origins. AAPG Bull. 2010, 94, 1811-1825.

(58) Aghli, G.; Moussavi-Harami, R.; Tokhmechi, B. Integration of sonic and resistivity conventional logs for identification of fracture parameters in the carbonate reservoirs (A case study, Carbonate Asmari Formation, Zagros Basin, SW Iran). J. Pet. Sci. Eng. 2021, 186, No. 106782.

(59) Guo, Q.; Wang, X. Y.; Qu, L. A new method for identifying fractures in tight sandstone of a gentle structural area using well logs. Energy SCI. Eng. 2020, 8, 3909-3924.

(60) Wang, Y. B.; Yin, S.; Guo, M. Q.; Zhao, J. Z.; Li, J. Fracture logging evaluation of upper Paleozoic tight sandstone gas reservoirs in the eastern margin of the Ordos Basin. Fresenius Environ. Bull. 2020, 29, 1572-1580.

(61) Peacock, D. C. P.; Sandersonb, D. J.; Rotevatna, A. Relationships between fractures. J. Struct. Geol. 2018, 106, 41-53.

(62) Luo, B.; Wen, L.; Zhang, Y.; Xie, C.; Cao, J.; Xiao, D.; Guo, G. H.; Tan, X. C. Differential gas accumulation process of the Middle Permian Qixia Formation, Northwestern Sichuan Basin. Oil Gas Geol. 2020, 41, 393-406.

(63) Rashid, F.; Hussein, D.; Lawrence, J. A.; Khanaqa, P. Characterization and impact on reservoir quality of fractures in the Cretaceous Qamchuqa Formation, Zagros folded belt. Mar. Pet. Geol. 2020, 113, No. 104117.

(64) Xiang, N.; Xie, Y. G.; Shi, X. F.; Li, S. L.; Zhang, J. L. Analysis of shale structural fracture development characteristics and formation time in the strong deformation zone in the southern Qinshui Basin, China. Fresenius Environ. Bull.. 2020, 29, 7589-7598. 
(65) Jia, C.; Hu, C. C. Instability mechanism and control technology of longwall entries driving along the gob in a thick coal seam. J. Min. Strata Control Eng. 2020, 2, 43535.

(66) Huang, F. R.; Yan, S. X.; Wang, X. L.; Jiang, P. C.; Zhan, S. B. Study on infrared radiation characteristics of gneiss under uniaxial compression. J. Min. Strata Control Eng. 2021, 3, No. 013011.

(67) Fan, X. P.; He, Y. C.; Yang, C. J.; Wang, J. F. Evaluation of crustal inhomogeneity parameters in the southern Longmenshan fault zone and adjacent regions. J. Seismol. 2020, 24, 1175-1188.

(68) Xiao, D.; Cao, J.; Luo, B.; Zhang, Y.; Xie, C.; Chen, S. L.; Gao, G. H.; Tan, X. C. Mechanism of ultra-deep gas accumulation at thrust fronts in the Longmenshan Mountains, lower Permian Sichuan Basin, China. J. Nat. Gas Sci. Eng. 2020, 83, No. 103533.

(69) Pan, H.; Zhu, L.; Zhang, X. F.; Gu, W. Z.; Liu, Z. C.; Li, J.; Song, T. Q.; Qiu, F. Q. Distribution characteristics of deviatoric stress and control technology of surrounding rock at temporary water chamber group in deep mining. J. Min. Strata Control Eng. 2020, 2, No. 043033.

(70) Cai, Y. F.; Li, X. J.; Deng, W. N.; Xiao, W.; Zhang, W. K. Simulation of surface movement and deformation rules and detriment key parameters in high-strength mining. J. Min. Strata Control Eng. 2020, 2, No. 043511.

(71) Zhang, G. Y.; Yu, Q. G.; Zhao, Gb. Three-dimensional simulation of soft overburden "two-zone" height due to high-intensity mining in Shajihai Coal Mine. J. Min. Strata Control Eng. 2021, 3, No. 023519.

(72) Zanganeh, B.; Clarkson, C. R.; Yuan, B.; Zhang, Z. Z. Field trial of a modified DFIT (pump-in/flowback) designed to accelerate estimates of closure pressure, reservoir pressure and well productivity index. J. Nat. Gas Sci. Eng. 2020, 78, No. 103265.

(73) Barree, R. D.; Barree, V. L.; Craig, D. P. Holistic fracture diagnostics: consistent interpretation of prefrac injection tests using multiple analysis methods. SPE Prod. Oper. 2009, 24, 396-406.

(74) Li, Y.; Du, G. Reasonable width of narrow coal pillars in roadway driving with gas drainage hole. J. Min. Strata Control Eng. 2020, 2, No. 013007.

(75) Shar, A. M.; Abro, W. A.; Mahesar, A. A.; Lee, K. S. Simulation study to evaluate the impact of fracture parameters on shale gas productivity. Mehran Univ. Res. J. Eng. Technol. 2020, 39, 432-442.

(76) Zhang, F.; Jiang, Z. X.; Sun, W.; Zhang, X.; Zhu, L.; Li, X. H.; Zhao, W. Effect of microscopic pore-throat heterogeneity on gasphase percolation capacity of tight sandstone reservoirs. Energy Fuels 2020, 34, 12399-12416.

(77) He, S.; Li, H.; Qin, Q. R.; Long, S. X. Influence of Mineral Compositions on Shale Pore Development of Longmaxi Formation in the Dingshan Area, Southeastern Sichuan Basin, China. Energy Fuel 2021, 35, 10551-10561.

(78) Gao, F. Q. Use of numerical modeling for analyzing rock mechanic problems in underground coal mine practices. J. Min. Strata Control Eng. 2019, 1, No. 013004.

(79) Gao, F. Q. Influence of hydraulic fracturing of strong roof on mining-induced stress-insight from numerical simulation. J. Min. Strata Control Eng. 2021, 3, No. 023032.

(80) Lai, J.; Wang, G. W.; Pang, X. J.; Fan, X. C.; Zhou, Z. L.; Si, Z. W.; Xie, W. B.; Qin, Z. Q. Effect of pore structure on reservoir quality and oiliness in Paleogene Dongying Formation sandstones in Nanpu Sag, Bohai Bay Basin, Eastern China. Energy Fuels 2018, 32, 92209232. 